\title{
An Analysis of Premature Cracking Associated with Microstructural Alterations in an AISI 52100 Failed Wind Turbine Bearing Using X-Ray Tomography
}

\author{
Benjamin Gould ${ }^{1,2} *$, Aaron Greco ${ }^{1}$, Kenred Stadler ${ }^{3}$, Xianghui Xiao ${ }^{4}$
}

\begin{abstract}
:
Crack surrounded by local areas of microstructural alteration deemed "White etching cracks" (WECs) lead to unpredictable and premature failures within a multitude of applications including wind turbine gearbox bearings. While the exact cause of these failures remains unknown, a large number of hypotheses exist as to how and why these cracks form. The aim of the current work is to elucidate some of these hypotheses by mapping WEC networks within failed wind turbine bearings using high energy X-ray tomography, in an attempt to determine the location of WEC initiation, and the role of defects within the steel, such as inclusions or carbide clusters. Four completely subsurface WECs were found throughout the presented analysis, thereby confirming subsurface initiation as method of WEC formation. Additionally, a multitude of small butterfly like cracks were found around inclusions in the steel, however further analysis is needed to verify if these inclusions are initiation sites for WECs.
\end{abstract}

Key Words: White Etching Cracks; X-Ray Tomography; Bearing Failures; Microstructural Alterations; Premature Fatigue

Acknowledgments:

This work is supported by the U.S. Department of Energy Office of Energy Efficiency and Renewable Energy, Wind and Water Power Technology Office under Contract No. DE-AC02-06CH11357. The authors are grateful to DOE Project Managers Mr. Michael Derby and Mr. Nick Johnson for their support and encouragement. The authors would also like to acknowledge the assistance provided by our colleagues at Argonne National Laboratory's Tribology Section, especially Dr. Maria De La Cinta Lorenzo Martin for her assistance with electron microscopy and Dr. Oyelayo Ajayi for his helpful discussion on metallurgy. As well as Dr. David L. Burris of the University of Delaware's department of Mechanical Engineering for serving as an advisor over the course of this work. This research used resources of the Center for Nanoscale Materials and Advanced Photon Source, a U.S. Department of Energy (DOE) Office of Science User Facility operated for the DOE Office of Science by Argonne National Laboratory under Contract No. DE-AC02-06CH11357.

(C) 2016. This manuscript version is made available under the Elsevier user license http://www.elsevier.com/open-access/userlicense/1.0/ 


\subsection{Introduction:}

Cracks surrounded by local areas of altered microstructure are known to lead to unpredictable failures, at a number of loading cycles significantly lower than what is predicted by classical rolling contact fatigue, in applications such as: wind turbine gearbox bearings, hydrogen fuel cell bearings, Marine Pod drive bearings, automotive alternator bearings, driveline transmission bearings, and aircraft turbine bearings [1-10]. Recent research efforts into this topic have been driven by the wind turbine community due the prevalence of this failure mode, as well as the excessive cost associated with turbine downtime as well as expensive component replacement. According to the Gearbox Reliability Database maintained by the National Renewable Energy Laboratory (NREL), bearing failures account for over $60 \%$ of all wind turbine gearbox (WTG) failures, and axial cracking associated with associate microstructural alterations represent over $70 \%$ of all WTG bearing failures.

These observed cracks, deemed "White Etching Cracks" (WECs) are described as broad branching crack networks that contain local areas of microstructural alteration, that ultimately lead to macro-pitting/spalling in bearings (sometimes referred to as White Structure Flaking), examples are shown in Fig. 1. The microstructural alterations themselves, known as White-Etching Areas (WEAs), are locations where the crystalline structure of the bearing steel has experienced a phase transformation, often identified as nano-grain ferrite [3,11-18], which is between $30-50 \%$ harder than the surrounding matrix steel $[13,14,16,19]$. WEA's are known to occur in martensitic through hardened steel [3,11,12,20-27], bainitic steel [20], and case carburized steel [5,14,28-30]. If a bearing containing WECs is sectioned, and the subsurface is etched with Nital (nitric acid and ethanol), the microstructural alterations surrounding the cracks will appear white, hence the names 'White-Etching Areas' and 'White-Etching Cracks'.
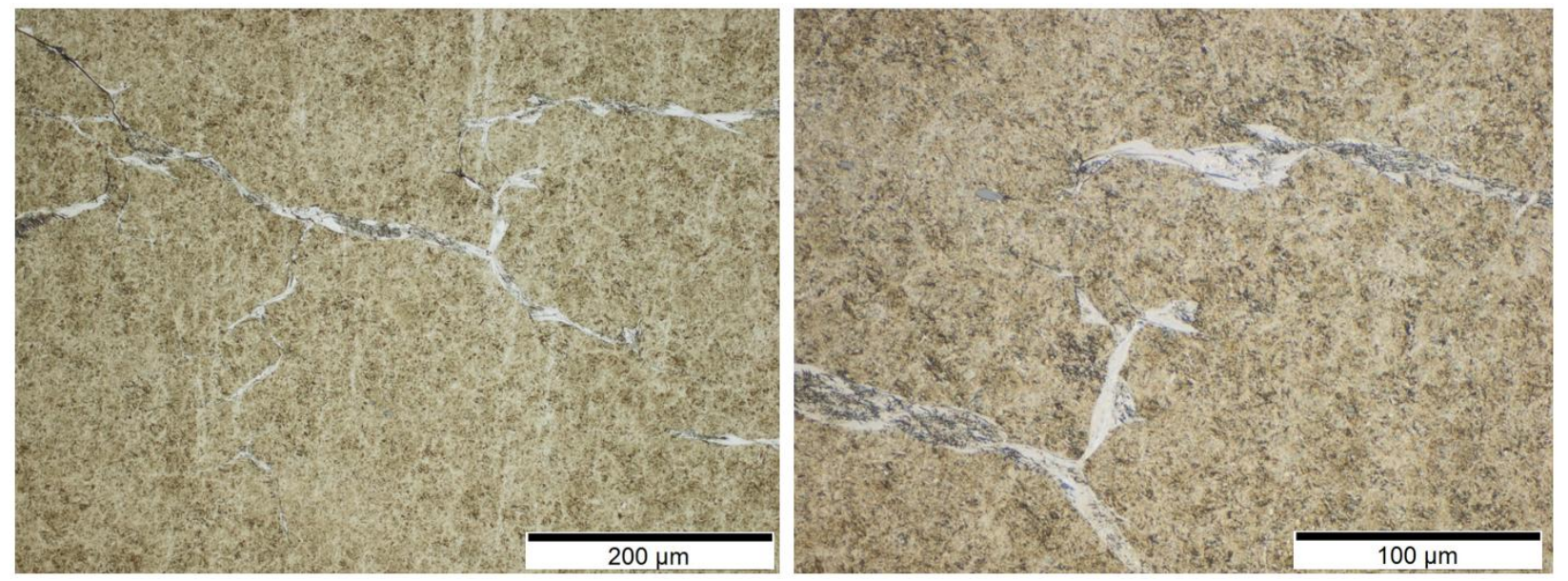

Fig. 1 Examples of WECs found in failed Wind Turbine Bearings

Local microstructural alterations due to tribological interactions are common, for example, WEA can be seen in other failure modes such as: scuffing [31,32], micropitting [33], fretting [34], and classical rolling contact fatigue $[14,35]$. In each of these distinct failure modes, including WECS, the morphology of the regions of altered microstructure are characteristically different, however, the fundamental mechanisms causing the transformation are, to some extent, similar. In order for there to be a local grain refinement and recrystallization of the material (forming the white-etching area) there must be some activation energy; for tribological components this is likely caused by excessive material deformation and/or additional thermal input. Though it is known that this excess in energy is required to form these alterations, the exact driver leading to this energy in WTGs has eluded the industry as well as academia.

\subsection{WEC Theories}


Several theories on the root cause of WECs can be found in literature [36,37]. A short introduction of several popular root cause hypotheses will be given in order to illustrate the need for a deeper investigation of crack systems in failed components.

For clarity, the leading root cause theories that attempt to explain WEC generation have been grouped into two categories; mechanical influences (Fig. 2) and external (or environmental) influences (Fig. 3). This does not exclude combinations of both categories (e.g. stresses combined with water contamination, or stresses combined with mixed friction and slip conditions, etc.). It should also be mentioned that the presented overviews are simplified and more theories exist in the community; especially when discussing the chain of events until failure at a higher degree of detail.

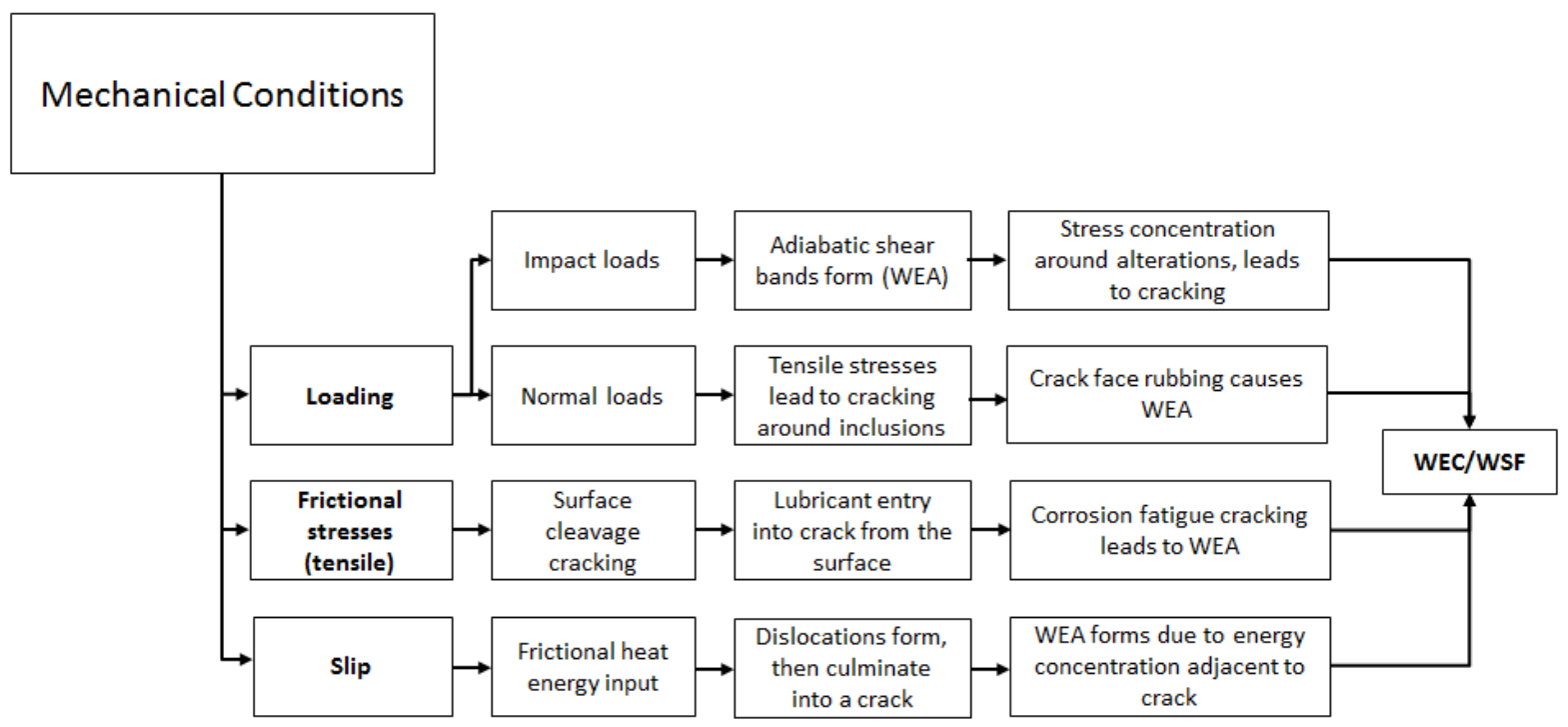

Fig. 2 A simplified overview of the mechanical drivers that could influence WEC formation in bearing steel.

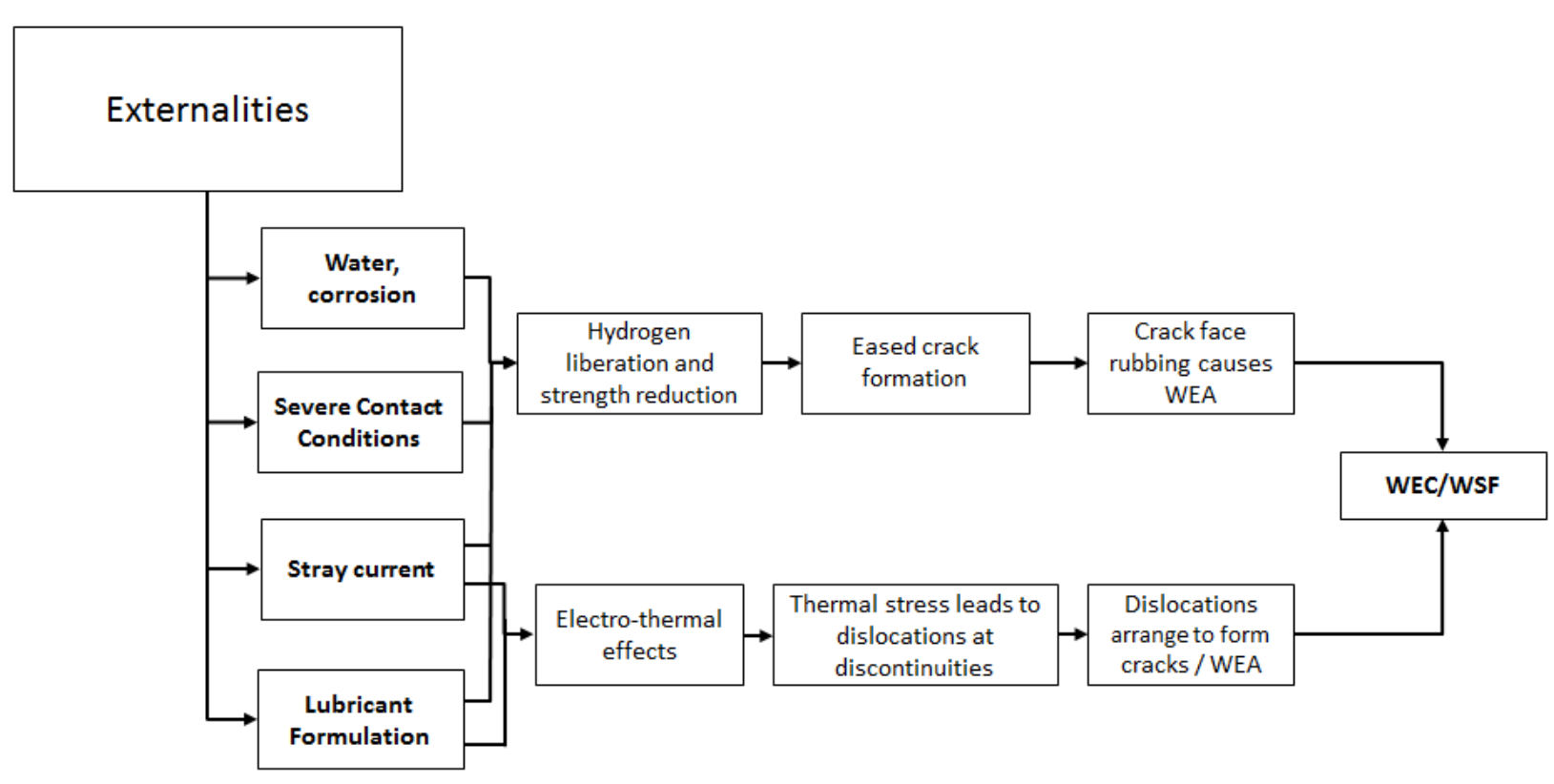

Fig. 3 A simplified overview of the external or environmental factors that could influence WEC formation in bearing steel 
In the category mechanical loads (Fig. 2), one theory states that WECs are the result of high strain rate events resulting in altered microstructure (WEA) termed adiabatic shear bands (ASBs) [38-40]. These ASBs form due to an impact load, in the subsurface of the bearing, at a depth corresponding to the maximum shear stress. The cracks would then form at the boundary between the shear band and the untransformed matrix, either at the instance of ASB formation, or over multiple over-rolling cycles due to the hardness and elastic modulus miss match between the alteration and the surrounding matrix.

Several authors [11,16-18,20,23,36,37,39-45] have proposed that cyclic stresses due to normal over-rolling and local tensile stresses (e.g. caused by structural deformations) lead to the accumulation of strain energy around inhomogeneities (e.g. inclusions, voids, carbides, etc.) resulting in plasticity, material decay (sometimes seen as dark etching regions (DER)) and finally crack generation. The presence of inclusions alone may lead to induced tensile stresses due to the hardness mismatch with the tempered martensite matrix and poor coherence between the oxide particle and matrix $[11,20,46]$. The crack generation will consequently lead to the formation of WEA around the crack due to crack face rubbing and (low temperature) re-crystallization.

Gegner [47] proposed the hypothesis that premature WEC failures are the result of cleavage cracks which initiate at the surface of the bearing due to tractive forces in mix-friction lubrication. The lubricant (eventually aged and/or contaminated with water) reacts inside these cleavage cracks at the fresh metallic crack faces, triggering a corrosion fatigue crack propagation process. This may lead to a hydrogen-induced microstructure transformation by means of hydrogen release from decomposition products of the penetrating oil on the rubbing blank metal crack faces that in turn further accelerate the crack propagation. Additionally, depending on the crack orientation, hydraulic effects will additionally push the crack propagation [48]. These effects, combined with cyclic shear stresses propagate the crack from the surface into the subsurface of the bearing steel.

Sliding between the rollers and raceway of bearings has long been postulated to aide in the formation of WECs, and its influence has been studied extensively [45,49-51]. The current authors [51] found that the direction of the surface tractive force due to sliding was a dominant driver if WECs would form within test samples. In a subsequent study [45] the authors discovered the presence of WECs within test samples was correlated to the cumulative frictional heat energy that the sample experienced over the entirety of the test (a value dominated by normal load and slip). It was postulated that this large cumulative energy, in combination with the strain energy of normal over-rolling, aid in atomic diffusion, leading to the formation of a large number of dislocations locally within the steel, appearing as DEA. If enough of these dislocations form, then stress relaxation can lead to the formation of a crack. This crack would then act as a point of significant energy concentration, as well as energy generation through crack face rubbing, exacerbating dislocation formation and carbon diffusion from the surrounding steel, leading to the formation of WEA.

In the category external or environmental factors (Fig. 3), water contamination, [52], stray current [53,54], severe contact conditions (low lambda, high sliding) and certain oil formulations (e.g. containing anti-corrosion sulphonates) [37,55] are seen as root causes for the onset of premature failures and WEC. Most authors believe that these conditions promote atomic hydrogen generation and subsequent penetration into the bearing steel, resulting in the acceleration of rolling contact fatigue mechanisms. In other words, accelerated fatigue caused by hydrogen enhanced local plasticity (HELP) leads to fast material decay (sometimes associated with DER generation), crack initiation (preferable around inhomogeneities), WEA decoration, and finally WECs / spalling. Although hydrogen embrittlement is often viewed as a driver for WEC formation, it was recently shown that WECs can form in an environment completely devoid of hydrogen [56].

Recently, work by Ščepanskis et al [57], presented an additional theory to how externalities, namely electricity, could lead to the formation of WECS. It is hypothesized that self-charging and discharging of lubricants results in a localized transient current flow that causes local electromagnetic induction that passes into the subsurface of the steel, causing successive accumulation of distortion in the microstructure later undergoing a sudden transformation and rupture including carbides. This would lead to the local generation of supersaturated nano- 
crystalline ferrite (or WEAs). The WEAs in turn would initiate cracks, due to the difference in hardness compared to the surrounding microstructure.

\subsection{Crack Characterization}

Clearly, there are a large number of scientifically plausible hypotheses as to the drivers of WEC formation in wind turbine bearings. Therefore, an observational study as to the process of WEC initiation would help significantly in elucidating some of the above proposed hypotheses. For example, the observation of a completely subsurface crack network would prove the possibility of subsurface initiation; while the observation of only surface connected cracks could prove that lubricant elements or other contaminates are required to enter into the subsurface through a crack pathway that then promote the crack propagation. Additionally if a crack was observed without associated WEA some comments could be made as to if the alterations form before or after the crack network.

Previous attempts at mapping WEC networks, and identifying surface vs. subsurface initiation, were done using a process called serial sectioning [43]. This consisted of slowly polishing away at a surface and taking optical images every $\sim 3-5 \mu \mathrm{m}$. These images where then compiled and viewed as a two dimensional slide show. However, to view a three dimensional crack network, the cracks in each one of these two dimensional images needs to be hand traced using a stylus. These traced images are then superimposed on to one another using computer software. This process is very tedious; it requires 100's of polishing and etching steps to image even the smallest of cracks.

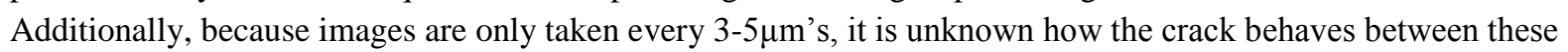
sections. The results of this previous work using this serial sectioning technique has suggested that WECs can initiate in the subsurface of bearing steel, seemingly stemming from inclusions [58,59].

A non-destructive evaluation (NDE) method could provide a more accurate and faster alternative to the process of serial sectioning. While ultrasonic mapping has been used extensively as an NDE method there are severe limitations in the application of this approach to study crack networks in high detail. Ultrasonic mapping can provide the general location of a crack but lacks the resolution to accurately characterize the crack morphology. Alternatively, X-ray micro-tomography can be used to map changes in density (cracks, inclusions, voids ect.) within samples of various material with a high degree of fidelity [60-67]. Its use with steel has been somewhat limited due the energy required to penetrate steel samples. Even the most powerful X-ray synchrotrons, require samples that are a few $\mathrm{mm}^{2}$ in cross-sectional area, in order to provide accurate reconstructions. Within steel, X-ray tomography has been used to: map void and cavity formation during tensile loading tests leading to necking [63], study the distribution of voids formed during manufacturing [62], as well as to study surface damage such as pitting corrosion [64], and stress corrosion cracking [61]. However, to the author's knowledge, X-ray tomography has not been used to study crack initiation within bearing steel samples.

This paper will describe the procedure and findings of applying X-ray micro-tomography as well as metallographic post-analysis to wind turbine bearing from the field; the initial results of this work was previously presented at the Wind Turbine Tribology Seminar hosted by Argonne National Laboratory in the fall of 2014 [68]. The authors intend to use the high accuracy of the tomographic approach, paired with selective sectioning to elucidate the process of WEC formation within field bearings. Particularly with aim to address the following question: are the cracks subsurface or surface initiated, are there other forms of microstructural alteration alongside the WEA, do the cracks consistently interface with inclusions. These findings can help in clarifying the onset of crack / WEC formation and further reduce the above mentioned root cause theories to the most plausible ones.

\subsection{Technique}

\subsection{Sample preparation}

For the current study, four samples were extracted from the inner ring of a SKF NJ2334 cylindrical roller bearing removed from a utility scale wind turbine gearbox, located on the high speed shaft. The material is a through hardened AISI 52100 martensitic steel. The same bearing was used in a previous study [19]. 
The samples were cut from locations on the wear track, where no optically visible surface cracking was present, in the close vicinity to areas of visible surface damage on the sample. This approach was used with the intent to capture cracks in the early stages of formation, and thus avoiding cracks that may have already propagated to the surface; while still including areas of the bearing that show signs of surface contact between the roller and raceway. The size of the extracted samples used for X-ray tomography varied, however, the maximum size that could be accommodated within the beamline is $1.6 \mathrm{~mm} \times 1.6 \mathrm{~mm} \times 20 \mathrm{~mm}$ with the longest dimension oriented in the axial direction. This size limit was required to attain the resolution needed to detect cracks in the sample. First, a large section $(2 \mathrm{~cm} \times 2 \mathrm{~cm} \times 2 \mathrm{~cm})$ was extracted from the bearing using a high speed liquid cooled abrasive cut off wheel. This larger section was then cut to size using a precision liquid cooled slow speed saw with a cubic boron nitride blade.

\subsection{X-Ray Micro-tomography}

The tomography experiments were performed at 2-BM beamline of Advanced Photon Source at Argonne National Laboratory. The samples were mounted using clay with the longest dimension oriented vertically (Fig. 4 a), before being placed into the experimental chamber (Fig. 4 b). The 2-BM beamline has a bending magnet source with usable X-ray energy up to $200 \mathrm{keV}$ [69]. In these experiments, the X-ray beam from the source was filtered with $15 \mathrm{~mm} \mathrm{Si}$ and $20 \mathrm{~mm}$ glass filters. The strong filtration makes the $\mathrm{X}$-ray mean energy $(60 \mathrm{keV})$ high enough to penetrate the steel samples while beam hardening effects are minimized to ignorable level. The samples were imaged with a PCO.edge camera that is coupled with a long working distance Mitutoyo 10x lens and 10 $\mu \mathrm{m}$-thick LuAG:Ce scintillator. The scintillator converts the samples' X-ray projection images into visible light images, and the microscope lens magnifies the images. The images are then recorded by the camera. A sample is rotated by a rotation stage and 1500 images are taken evenly at rotation angles in $0-180^{\circ}$ angle range, each with field of view of $1.664 \mathrm{~mm}$ by $1.404 \mathrm{~mm}$ and a pixel size of $0.65 \mu \mathrm{m}$. These images are then reconstructed into user visible content using gridrec tomographic reconstruction algorithm [70] implemented in Tomopy, an open source tomographic reconstruction toolbox [71]. Before the tomographic reconstruction, the sample projection images were normalized by the reference beam images. Wavelet-Fourier ring removal filtering [72] was applied to each sinogram. Singledistance Paganin phase retrieval [73] was applied to each normalized projection image to reduce the edge enhanced contrast around domain boundaries and increase the contrast between different material phases.
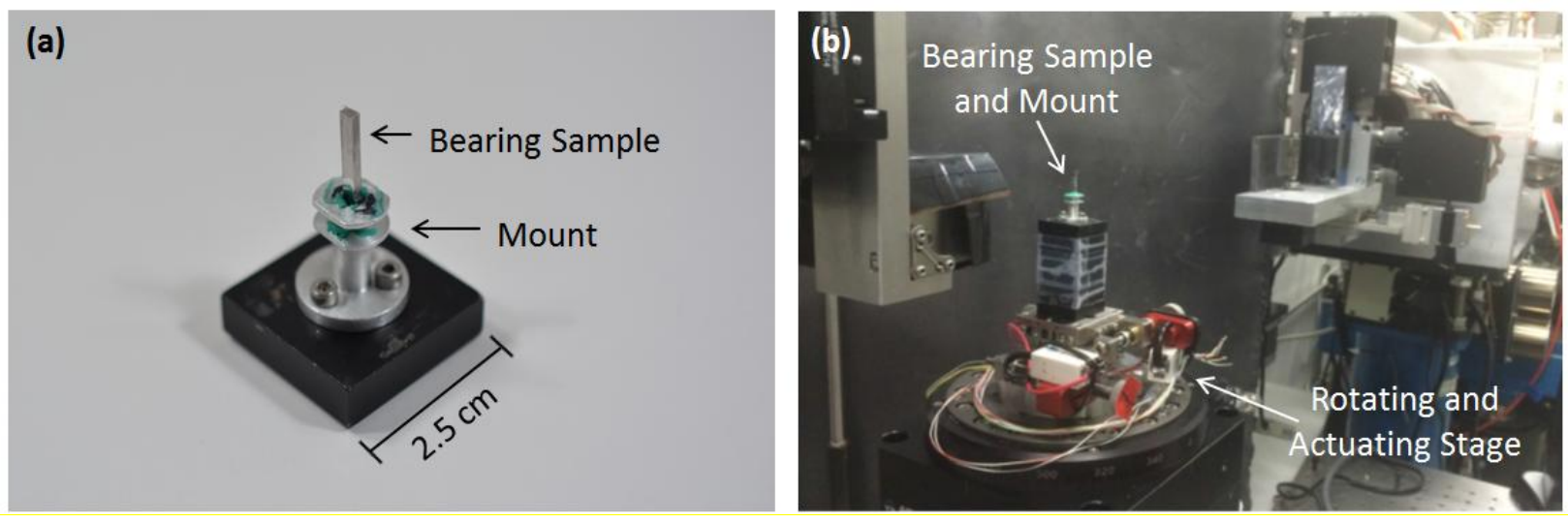

Fig. 4 (a) A steel sample affixed to a mount using clay before being placed into the beamline and (b) The sample placed into the experimental chamber just before beamline imaging

The output of scanning an entire sample using micro-tomography is a series of $1.664 \mathrm{~mm} \times 1.664 \mathrm{~mm} \mathrm{x}$ $1.404 \mathrm{~mm}$ rectangular prisms referred to as 'projects'. Each of the projects is comprised of 2040 individual two dimensional grey scale slices each spaced $0.65 \mu \mathrm{m}$ apart, as illustrated in Fig. 4. The brightness and contrast of these slices was then altered, and the influence of reconstruction and imaging artifacts was minimized through the use of a sliding paraboloid background subtraction technique offered in the commercially available software Image $\mathrm{J}$. The 
tomography result maps changes in density; therefore, each two dimensional slice will show signatures of discontinuities in the density within the material e.g. cracks, inclusions, or voids. However, the subtle differences in density between the original steel crystalline structure and any alteration (such as WEA) are not likely to be observable in the tomography scan. An example of a two dimensional (x,y) tomographic slice, which has been annotation to explaining the observable features, including edges of the sample, inclusions/voids, and cracks, is shown in Fig. 5. The features shown in Fig. 5c represent singular discrete areas of density contrast, typically representing either material voids or inclusions. These two features are indistinguishable from one another through the tomography analysis. The circular patterns that are visible at the bottom of Fig. 5a are visual artifacts that result from the data processing. These artifacts do not represent changes in the density within the sample and are neglected in the analysis.

To observe crack networks in three dimensions $(\mathrm{x}, \mathrm{y}, \mathrm{z})$ as opposed to slices $(\mathrm{x}, \mathrm{y})$, two different formats are used: videos showing the sequence of the slice images and three dimensional reconstructions. The videos represent a sequence of two dimensional images in the (x,y) plane from the perspective starting near the top of the crack, as oriented in Fig. 4 and moving down the z-axis with time. Additionally three dimensional reconstructions of the crack networks were prepared using a commercial image processing software called Avizo. The two dimensional slice images are imported into the program and stacked using the dimensional spacing, $0.65 \mu \mathrm{m}$. The program then represents the contrast in the gray-scaled images in a histogram which is used to identify the darker pixels that represent the inhomogeneity in the material density, which includes both cracks and inclusions/voids. These pixels are then plotted as a three dimensional representation of the tomography data.

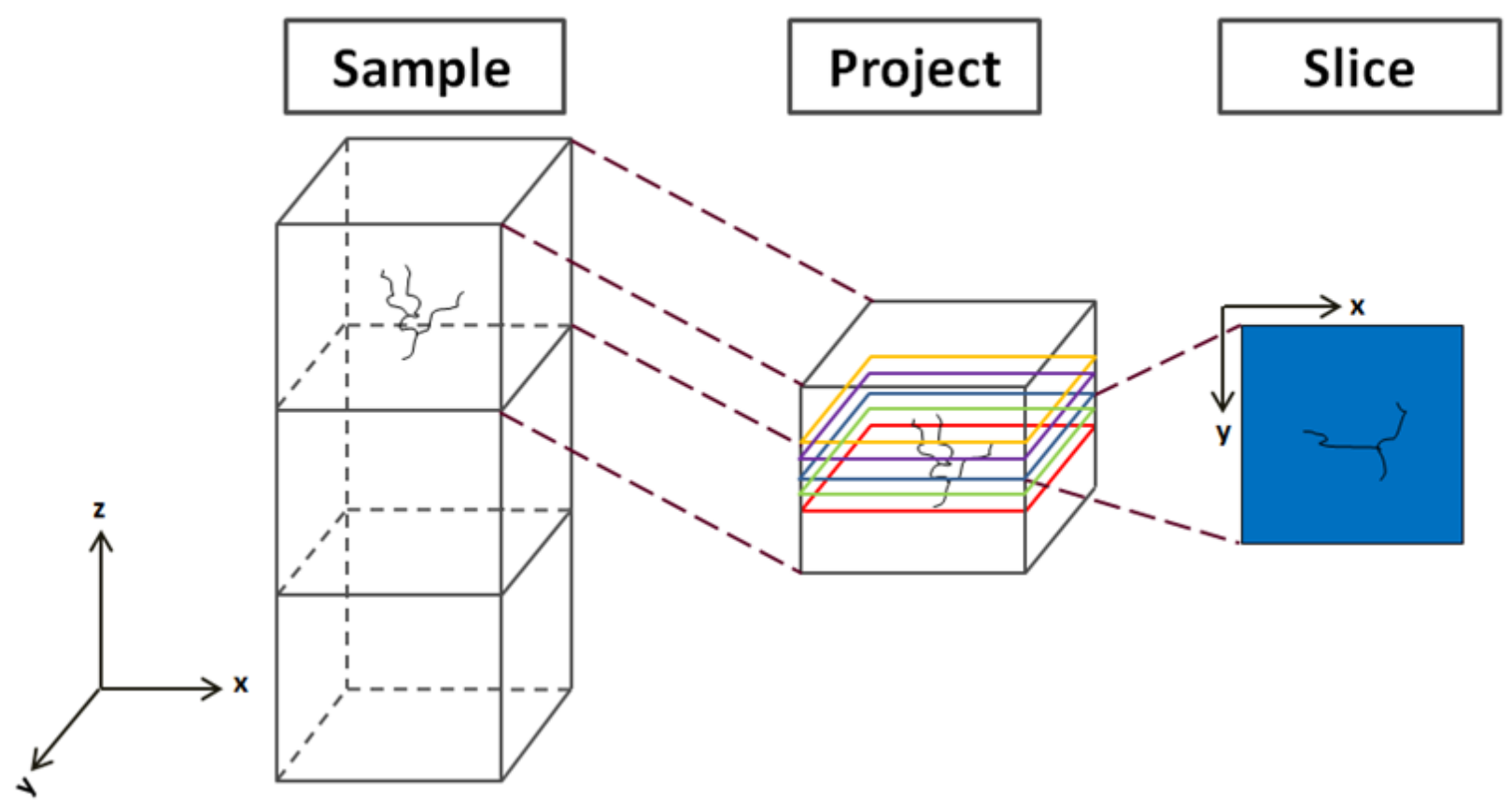

Fig. 4 An illustration as to how the scanned sample is broken down into individual projects and viewed as two dimensional slices 


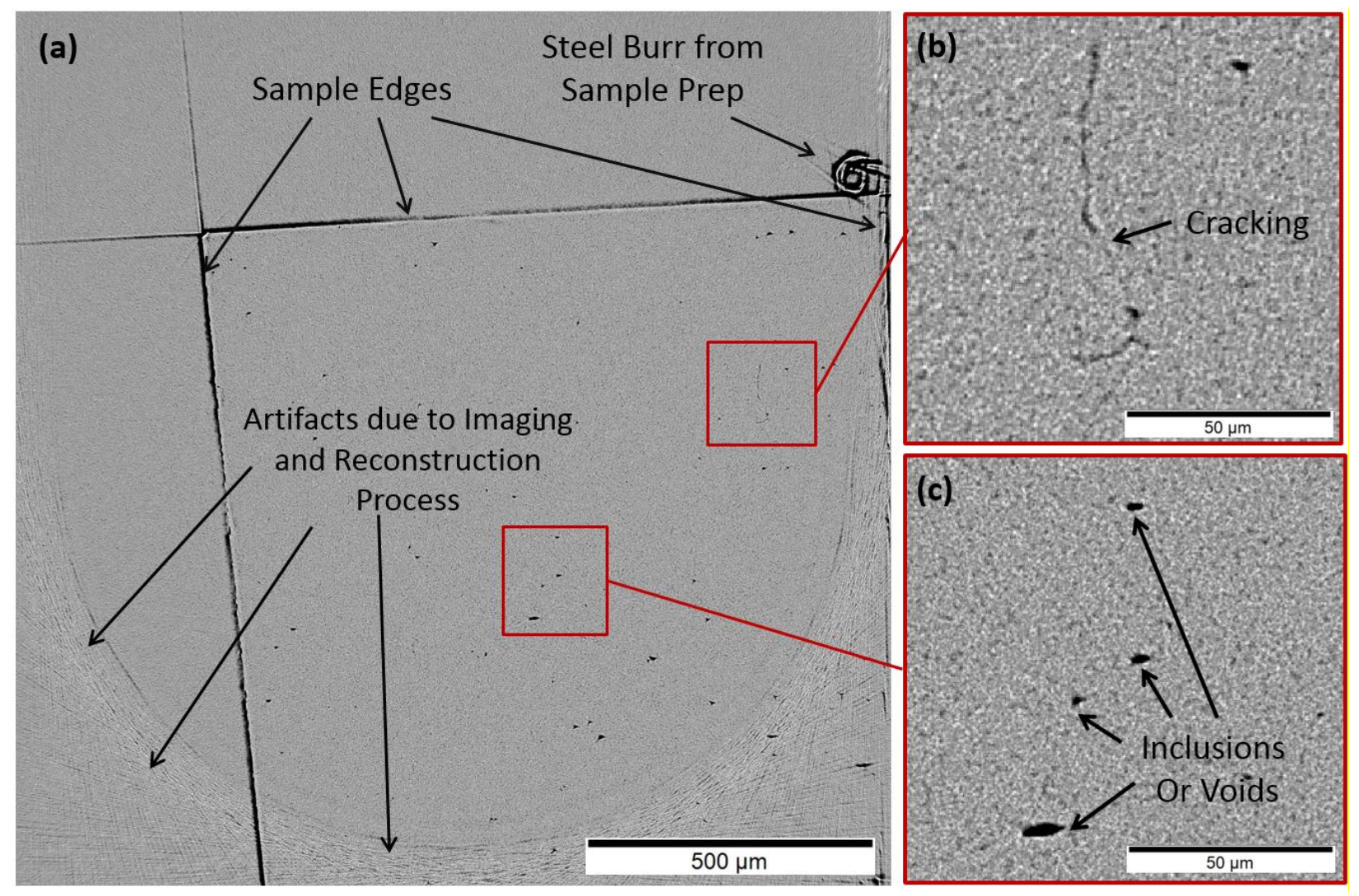

Fig. 5 An example two dimensional tomography slice showing representative features: (a) the sample edges and imaging artifacts, (b) cracking within the sample, and (c) inclusions or voids within the sample

2.3 Physical Sectioning and Analysis

In order to verify the presence of microstructural alterations around the detected cracks, as well as to determine the accuracy of the tomography reconstructions, selective physical sectioning was performed on one of the four samples after the X-ray tomography analysis. The sample was mounted in a Bakelite puck (with the zdimension of the sample oriented perpendicular to the polishing plane) and polished to multiple locations using a sequence of 220 grit grinding followed by $9 \mu \mathrm{m}, 3 \mu \mathrm{m}$, and $1 \mu \mathrm{m}$ diamond polishing medium. The locations of the sections were determined from the X-ray tomography results. The amount of material removal after each polishing step was determined through a process of measuring dimensional changes of an applied Vickers micro-indent, similarly to that presented in [58], in parallel with sample thickness measurements using a linear variable differential transducer (LVDT) sensor. A total of 32 sections were analyzed that spanned through the portion of the sample for which cracks were detected by tomography. At each section the sample was imaged using an Olympus STM6 optical microscope, before (Fig. 6a) and after (Fig. 6b) etching with a 3\% Nital (Nitric acid in ethanol) solution. Additional analysis was performed when necessary on a FEI Quanta 400F environmental scanning electron microscope (SEM), as shown in Fig. 6d. 

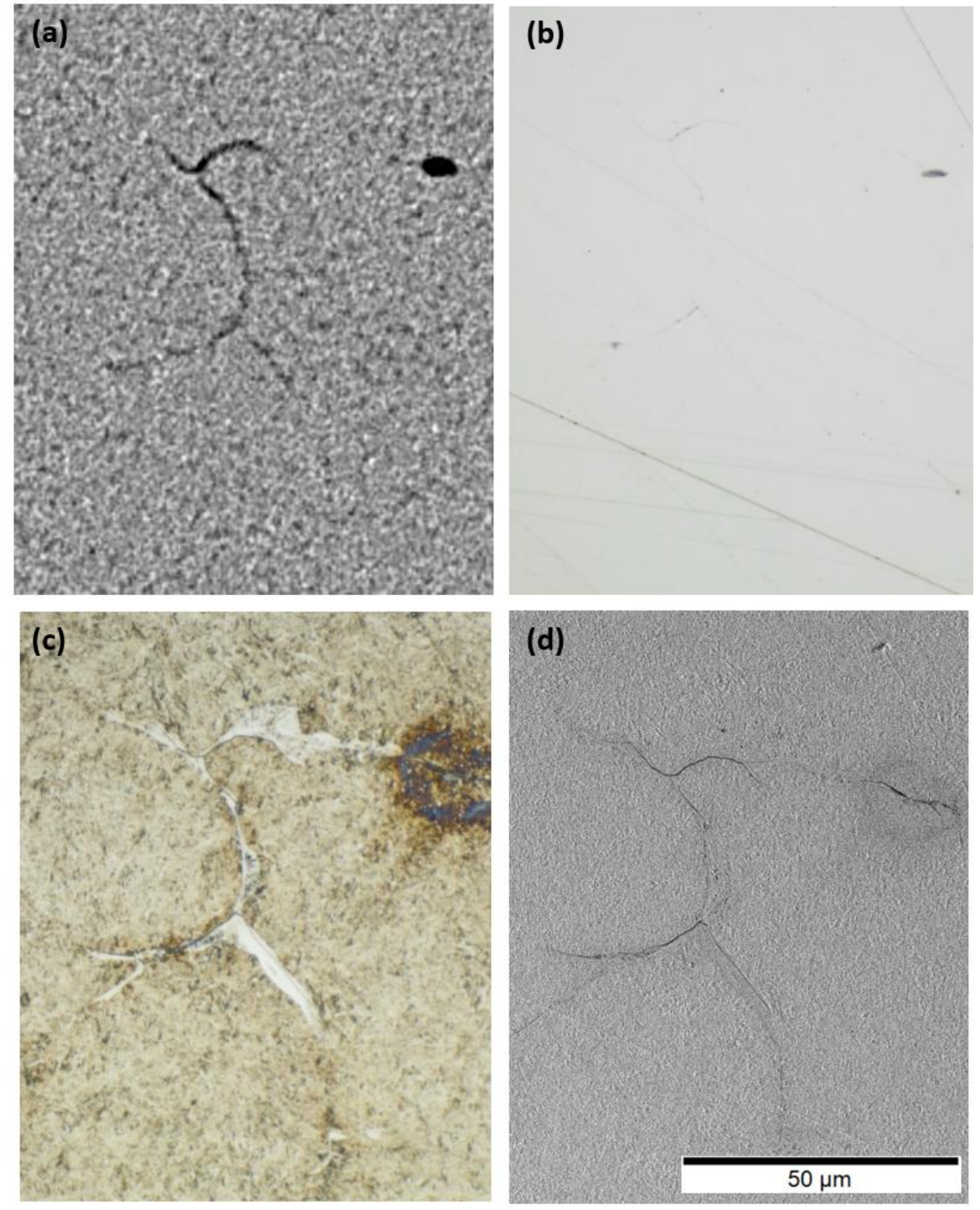

Fig. 6 Three images comparing the appearance of a crack (a) before any sectioning using tomography (b) after sectioning and polishing but before etching with $3 \% \mathrm{Nital}$, (c) after etching with $3 \% \mathrm{Nital}$, and (d) after etching using a scanning electron microscope

\subsection{Results}

Tomography scans were completed on four samples extracted from the bearing inner ring; the current work focuses on the results of one of these samples. The tomography analysis revealed four cracks that appeared to be completely encased within the bearing raceway and sample edges (subsurface). The cracks, which will be referred to as Cracks 1-4, span $620 \mu \mathrm{m}, 1330 \mu \mathrm{m}, 1070 \mu \mathrm{m}$, and $550 \mu \mathrm{m}$ in the axial direction respectively. A three dimensional diagram showing the relative location of these subsurface cracks within the sample is shown in Fig. 7. Multiple videos were created mapping the entirety of the four crack networks found within the sample; these videos are supplied as supplementary material and can be viewed online. These videos show circumferential planes moving axially through the bearing. All videos were created at 30 frames per second, which, at a separation distance of $0.65 \mu \mathrm{m}$ per frame, corresponds to an axial speed of $19.5 \mu \mathrm{m} / \mathrm{s}$ (30 frames $/ \mathrm{s} * 0.65 \mu \mathrm{m} /$ frame). Videos $1-4$ (corresponding to Cracks 1-4 respectively) show a cropped version of the entire tomography scan which includes the bearing raceway at the top of the screen. Videos 1-4 clearly illustrate that none of these crack branch to the raceway 
surface, therefore all four of our cracks must have initiated in the subsurface of the bearing. In Videos 5-8, the tomographical outputs are further cropped, and centered on Cracks 1-4 respectively, these videos are meant to be used to illustrate the crack morphology at a higher magnification. A three dimensional view of Crack 2 (the largest subsurface crack found) is shown in Fig. 8. This again shows that no portion of the crack network interacts with any of the sample edges or bearing raceway. Also observable in Fig. 8 are the multiple inclusions/voids distributed throughout the sample.

Representative two dimensional (x,y) tomography images of the four detected cracks, paired with optical microscopy images of their respective physical sections post etching, are shown in Fig. 9. This selective physical sectioning and etching revealed that all four of the cracks detected in this sample had associated local microstructural alterations evident from the appearance of WEA. From the nine to sixteen physical sections analyzed per crack network, it was evident WEA was present along a majority of the entire span of the cracks, as illustrated in Fig. 9.

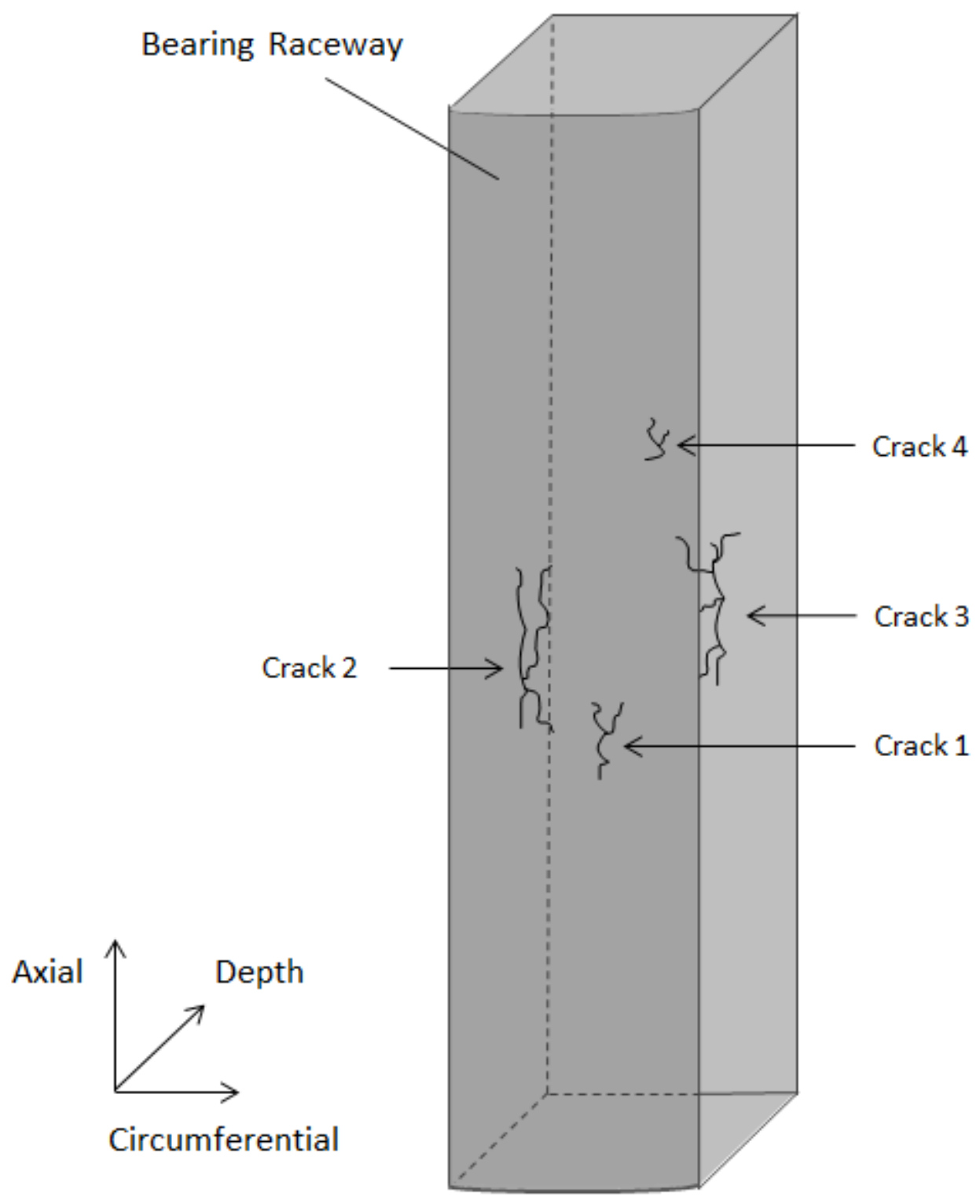

Fig. 7 An illustration of the relative location of the four subsurface cracks that were found in the sample 


\section{NOTE TO REVIEWERS AND EDITOR:}

Videos could not be imbedded in word document due to upload file size restrictions, the captions will be inserted below

Video 1 The entire span of Crack 1, the raceways has been included at the top of the video to illustrate that the crack is entirely subsurface.

Video 2 The entire span of Crack 2, the raceways has been included at the top of the video to illustrate that the crack is entirely subsurface.

Video 3 The entire span of Crack 3, the raceways has been included at the top of the video to illustrate that the crack is entirely subsurface.

Video 4 The entire span of Crack 4, the raceways has been included at the top of the video to illustrate that the crack is entirely subsurface.

Video 5 The entire span of Crack 1, this video has been cropped and centered on the crack to allow for a detail investigation of the crack morphology

Video 6 The entire span of Crack 2, this video has been cropped and centered on the crack to allow for a detail investigation of the crack morphology

Video 7 The entire span of Crack 3, this video has been cropped and centered on the crack to allow for a detail investigation of the crack morphology

Video 8 The entire span of Crack 4, this video has been cropped and centered on the crack to allow for a detail investigation of the crack morphology 
(a)

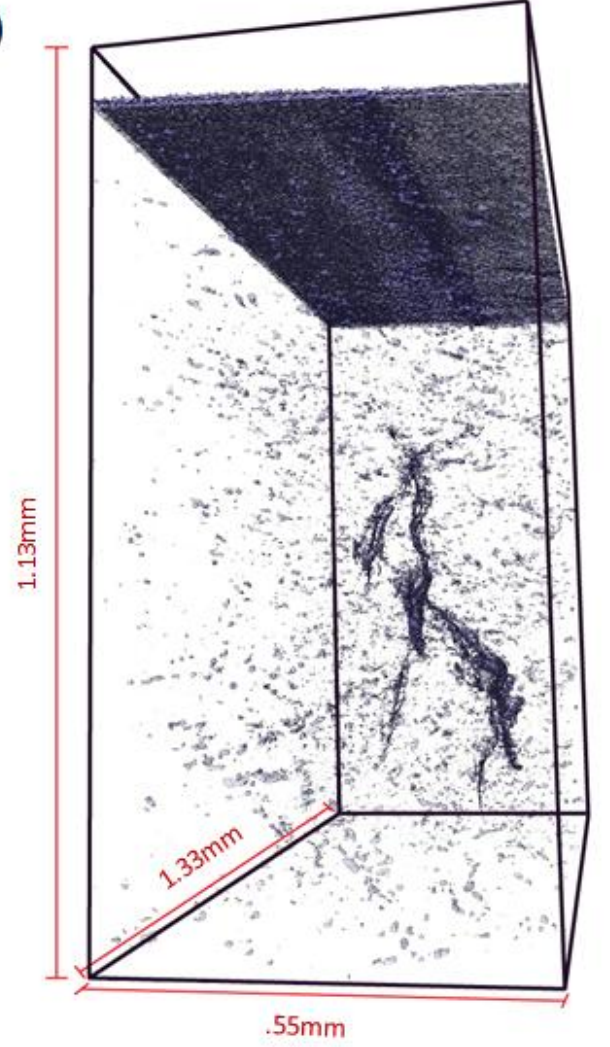

(b)

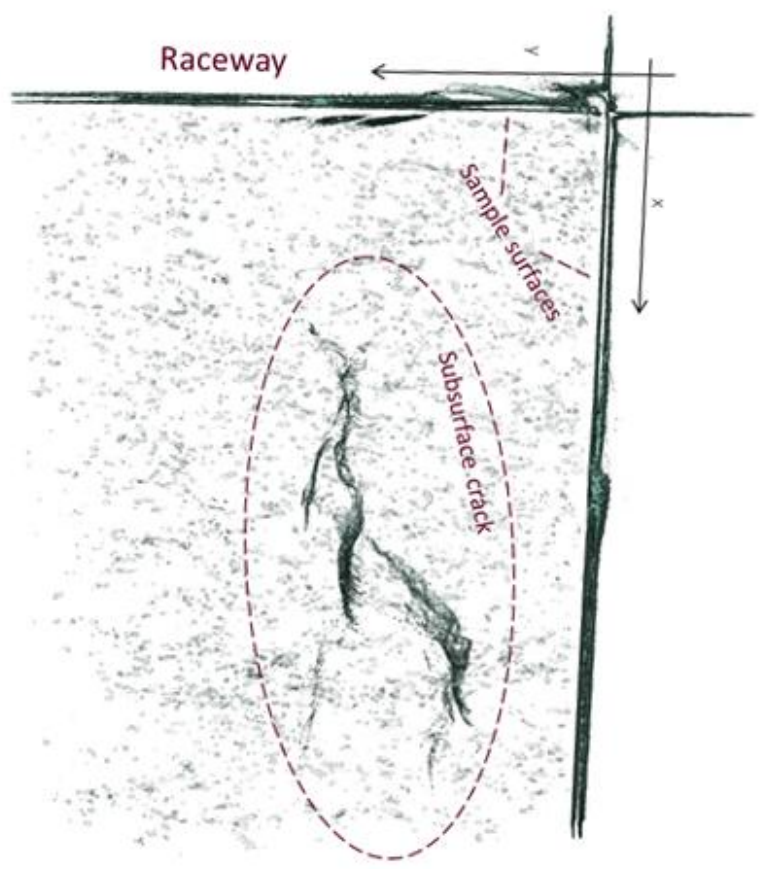

Fig. 8 Three dimensional views of Crack 2, showing the entirety of the crack as well as local changes in density, likely inclusions or voids, around it
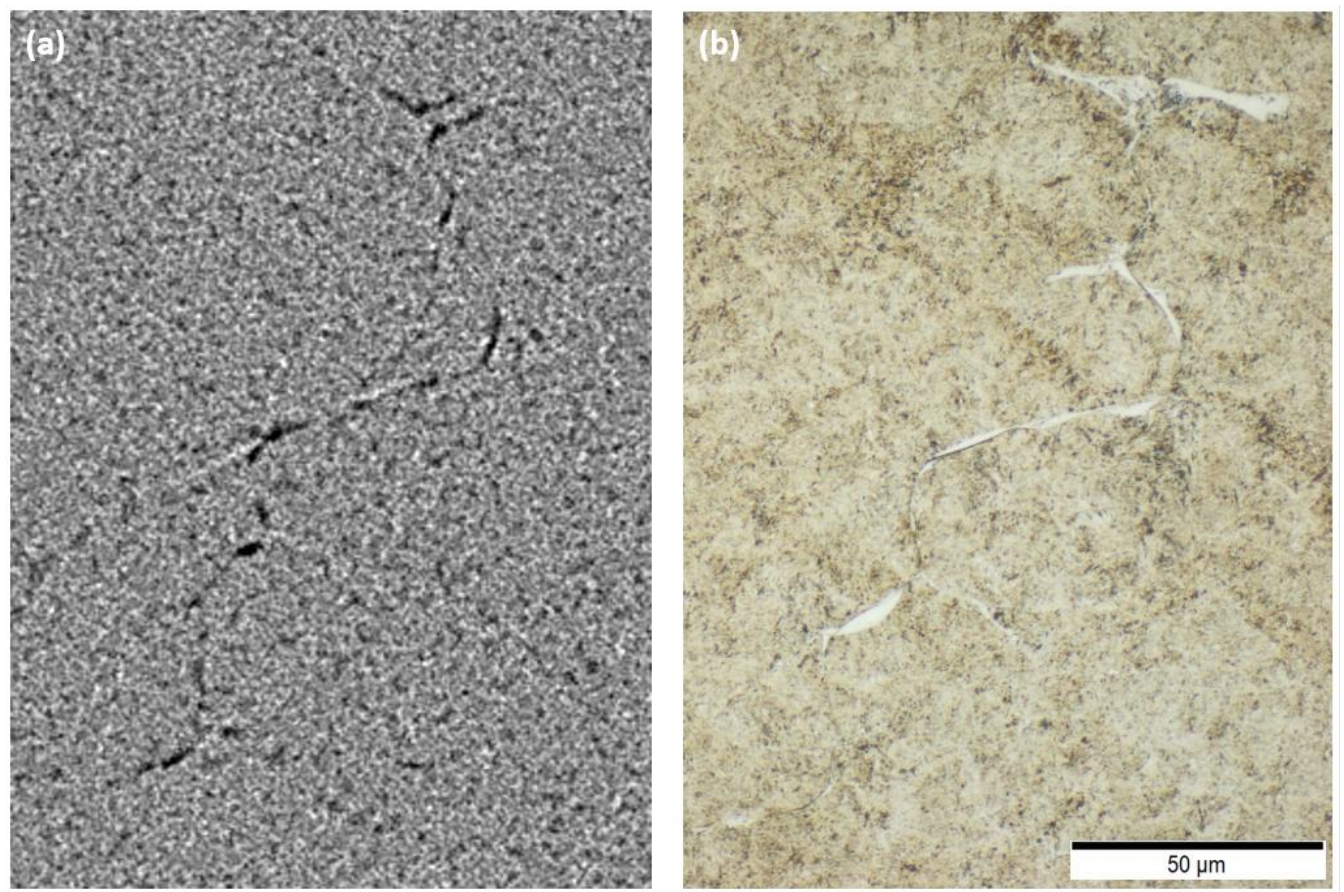

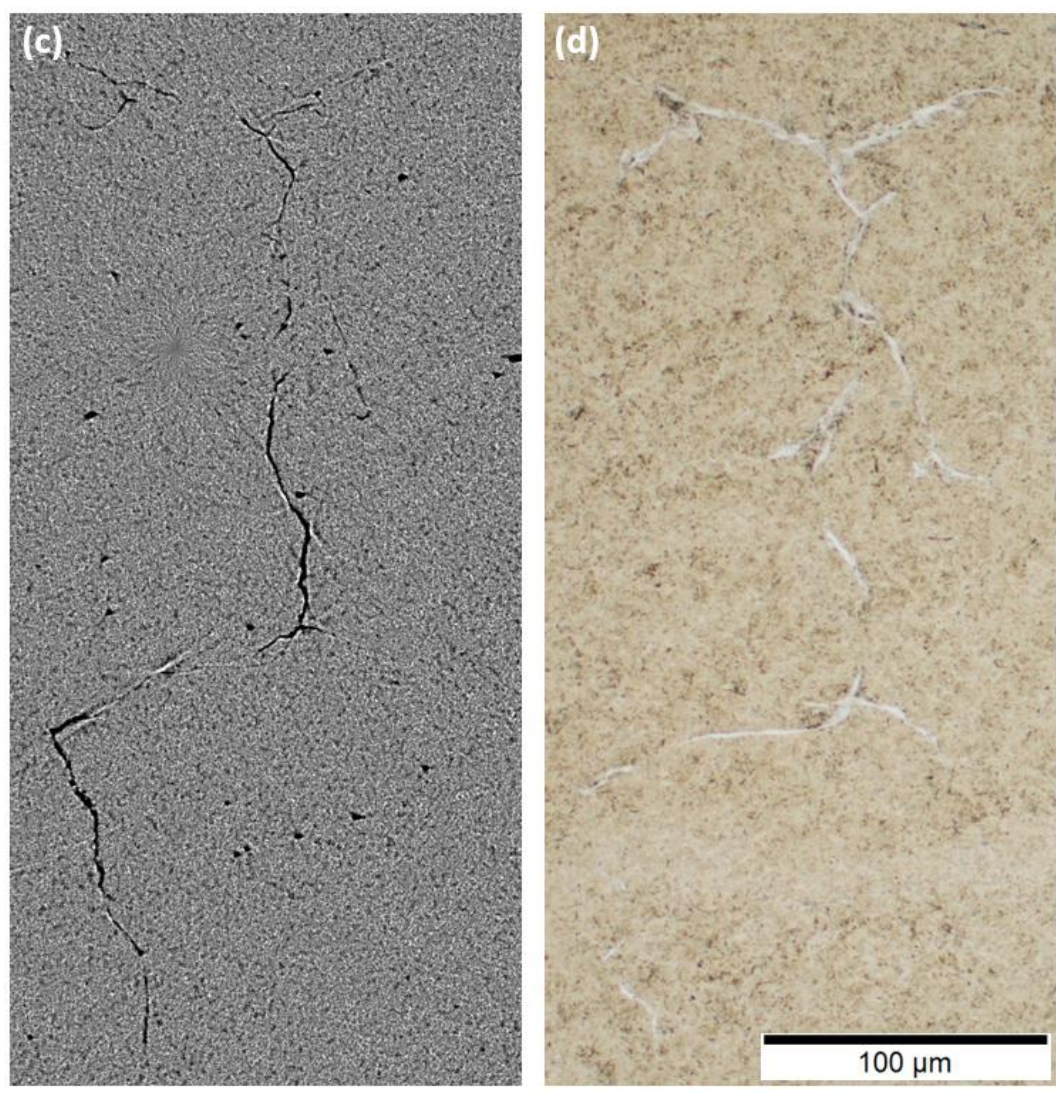

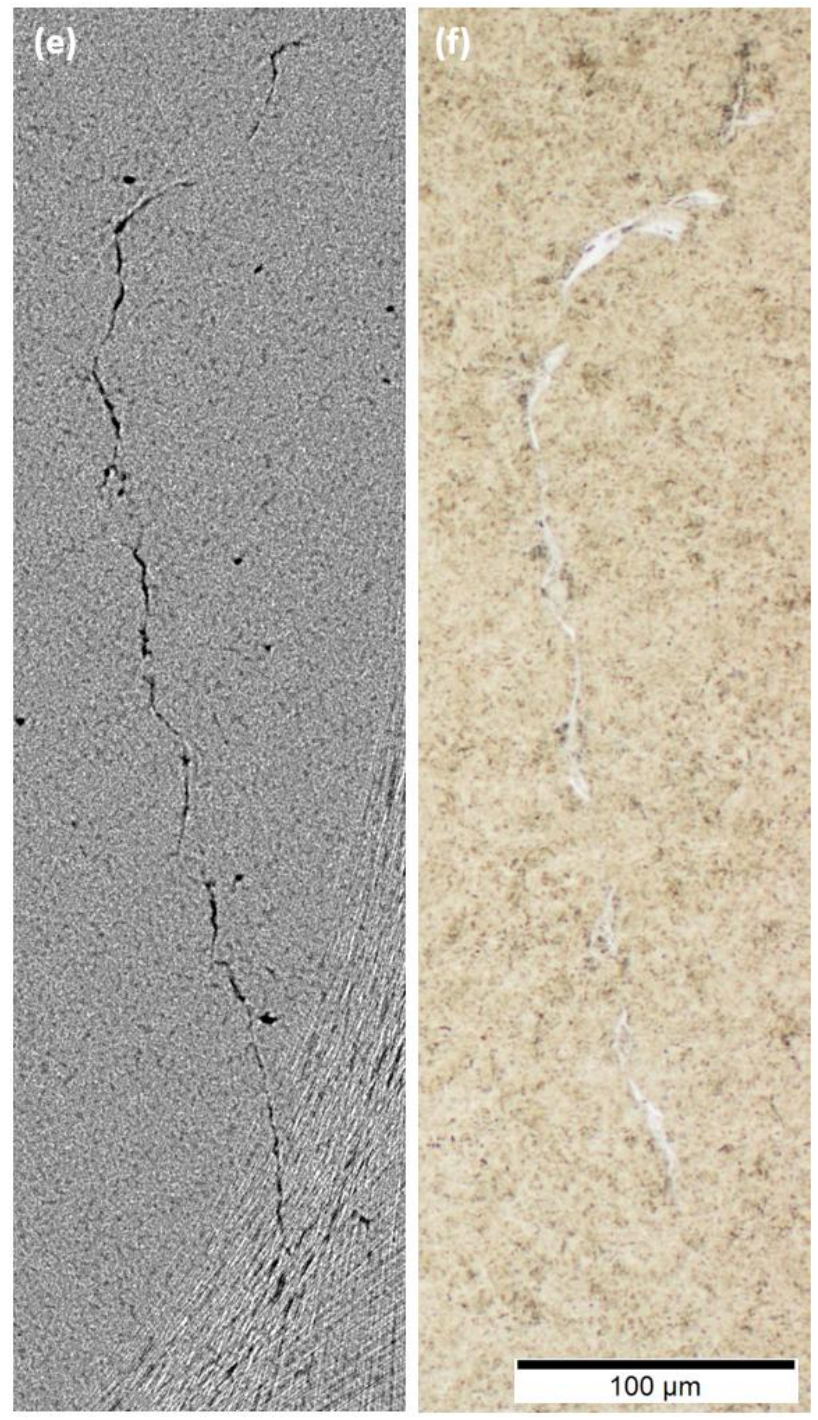

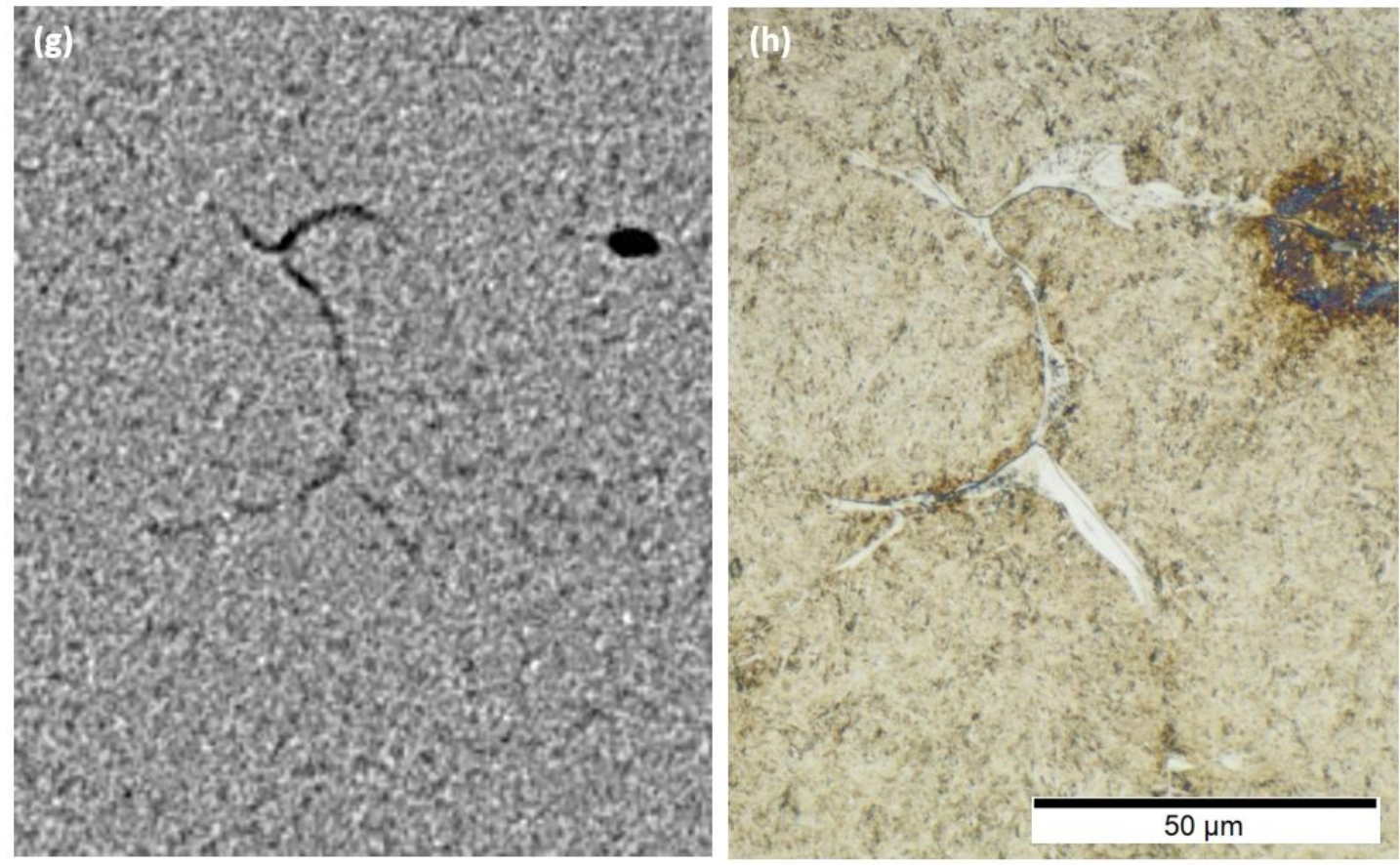

Fig. 9 Tomography images alongside etched optical images corresponding to the same location for (a) and (b) crack 1 , (c) and (d) crack 2, (e) and (f) crack 3, and (g) and (h) crack 4

The selective sectioning was also used to verify the accuracy of micro-tomography as a method for mapping crack networks. Specific sections were examined where the cracks appeared to move closest to the raceway or the edges of the sample. This was done in order to confirm that no branches of the cracks reached these edges. This investigation paired with the comparison between the tomography images and their optical counterparts (Fig. 9), can be used to support the claim that this X-ray micro-tomography imaging technique accurately represents the visible crack at each given section.

Many large dark spots, seemingly independent of the mapped crack networks can be observed in the tomography videos shown above, as well as in the three dimensional reconstructions shown in Fig. 8. As discussed above these contrast features appear due to the difference in density between a local region and the surround steel matrix, and likely correspond to an inclusion or a void. However, differentiation between an inclusions or a void requires subsequent physical cross-sectioning. Of the 32 physical sections performed, a vast majority of the inhomogeneities identified were inclusions, as shown in Fig. 10. This figure also demonstrates a limitation of the tomographical analysis; it is shown in Fig. 10b and c that small cracks exist surrounding these inclusions, however, these are not evident in the tomographic output shown in Fig. 10a. This is likely due to the fact that the crack size and width are not significant enough to produce a visible tomography signature. However it is also possible that the signature of the small cracks simply added to what appeared to be the signature of the inclusion. This is illustrated by the inclusion in the top left of the three images in Fig. 10, the signature of this inclusion appears much larger than the actual inclusion. It is important to note that this particular set of inclusions were not connected to any of the larger branching WEC crack networks found in the sample. Further study is needed to verify if these small inclusion-initiated cracks are the precursors for WEC. 

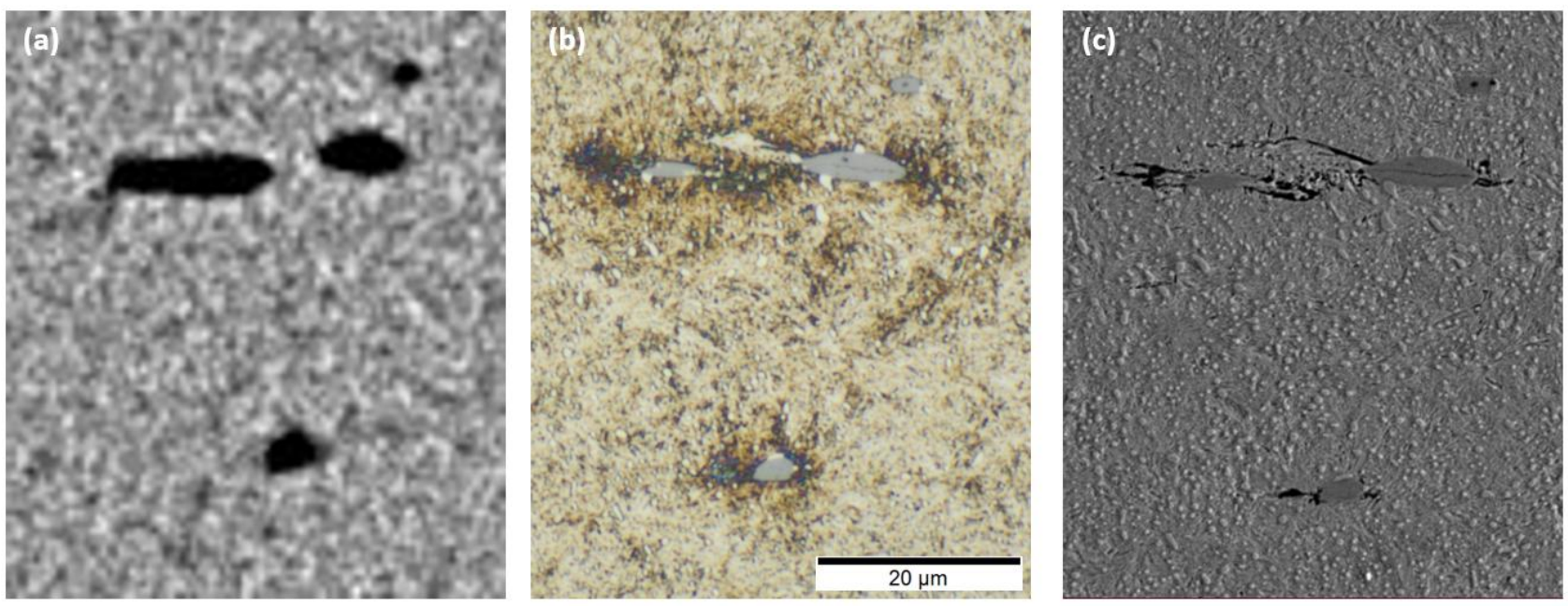

Fig. 10 (a) A tomography image (b) and etched optical image, and (c) an SEM micrograph of a cluster of inclusions surrounded by small amounts of cracking
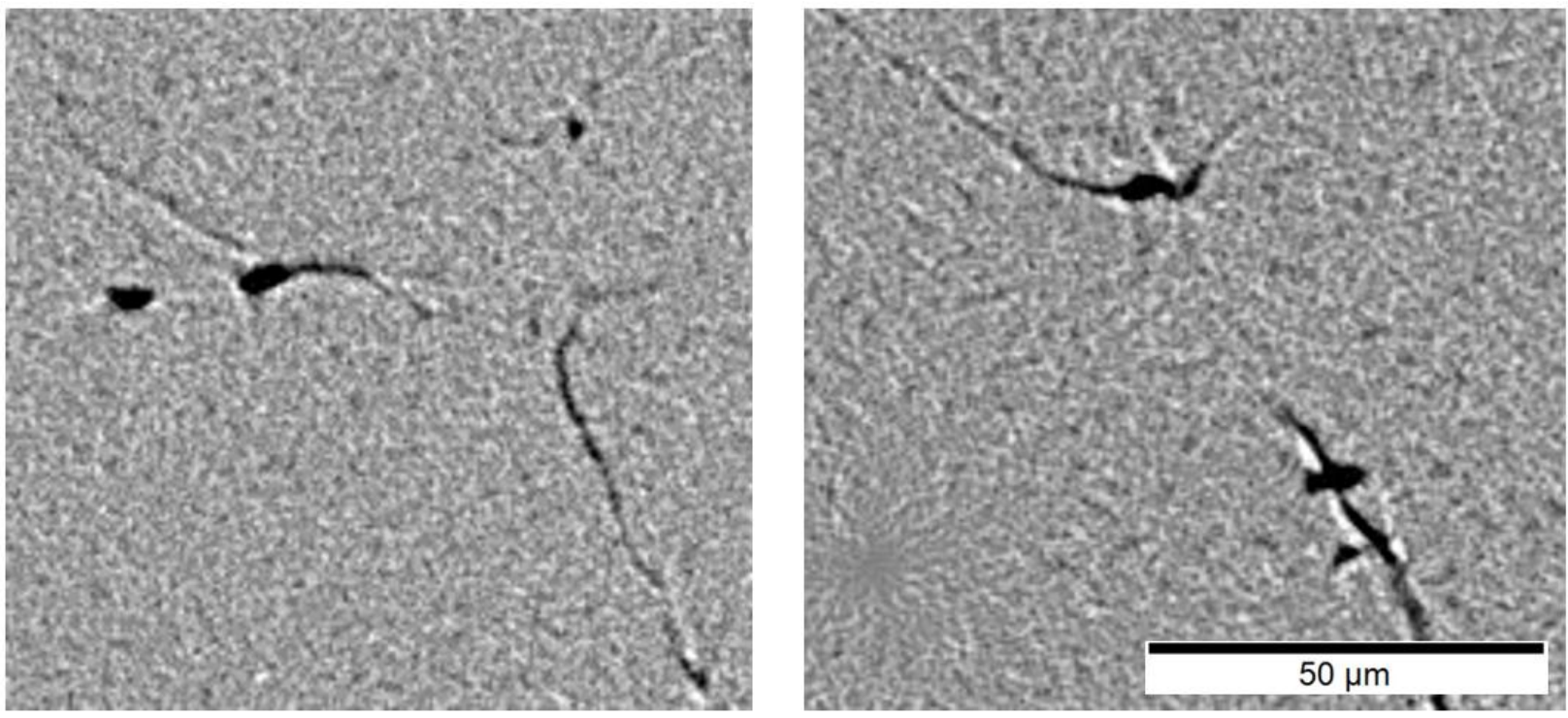

Fig. 11 Two tomography images showing instances where large signatures (presumably inclusions) interact with Crack 2

The tomography analysis also revealed locations of inclusion interaction within the WEC networks, for example locations of inclusion interaction with Crack 2 are shown in Fig. 11, Fig. 12, and Fig. 13. Additional analysis was performed on the inclusion shown in Fig 14 in order to identify its composition. Energy dispersive Xray spectroscopy (EDS) spot analysis using a $10 \mathrm{KeV}$ beam revealed that this particular inclusion consisted of an aluminum rich core, denoted by 1 in Fig. 12, surrounded by regions rich in manganese and sulfur, region 2 in Fig. 12. It is difficult to say if this inclusion was an initiation point for this WEC network. The optical image of the etched cross-section (Fig. 12b) shows alteration to microstructure, appearing as WEA, stemming from both sides of the inclusion, similar to a butterfly crack. This suggests that there is some correlation between the butterfly crack caused by the inclusion and the broader branching WEC. However, it is not clear if the WEC was dependent on inclusion induced cracking or if the WEC intersected the inclusion during propagation due to the influence of stress concentration. 

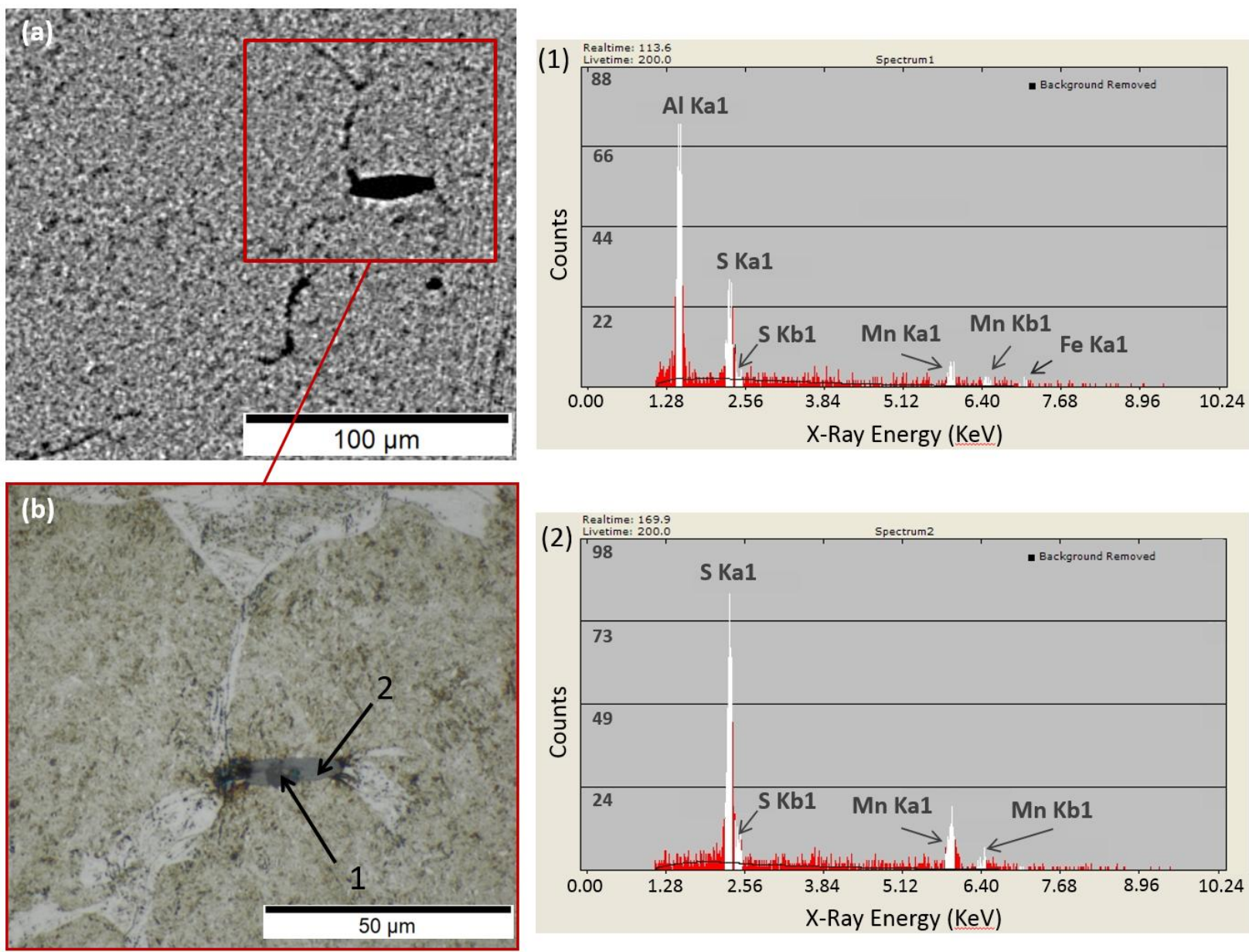

\section{Fig. 12 An example of an inclusion that was found interacting with Crack 2. EDS analysis showed a high concentration in aluminum in spot one, and a high concentration of sulfur and manganese in spot 2}

An example of the latter point (a preexisting crack intersecting an inclusion) is illustrated in Fig. 13. This shows tomography (Fig. 13a), optical (Fig. 13b), and SEM (Fig. 13c) of Crack 2 interacting with an inclusion. In Fig. $13 \mathrm{c}$ it can be observed that the inclusion itself is cracked through and has a small crack stemming from the right side of the inclusion, oriented horizontally, parallel to the raceway, while the larger crack network is oriented vertically, perpendicular to the raceway. This would suggest that this crack did not originate at this particular inclusion and instead interacts with the inclusion during propagation. 

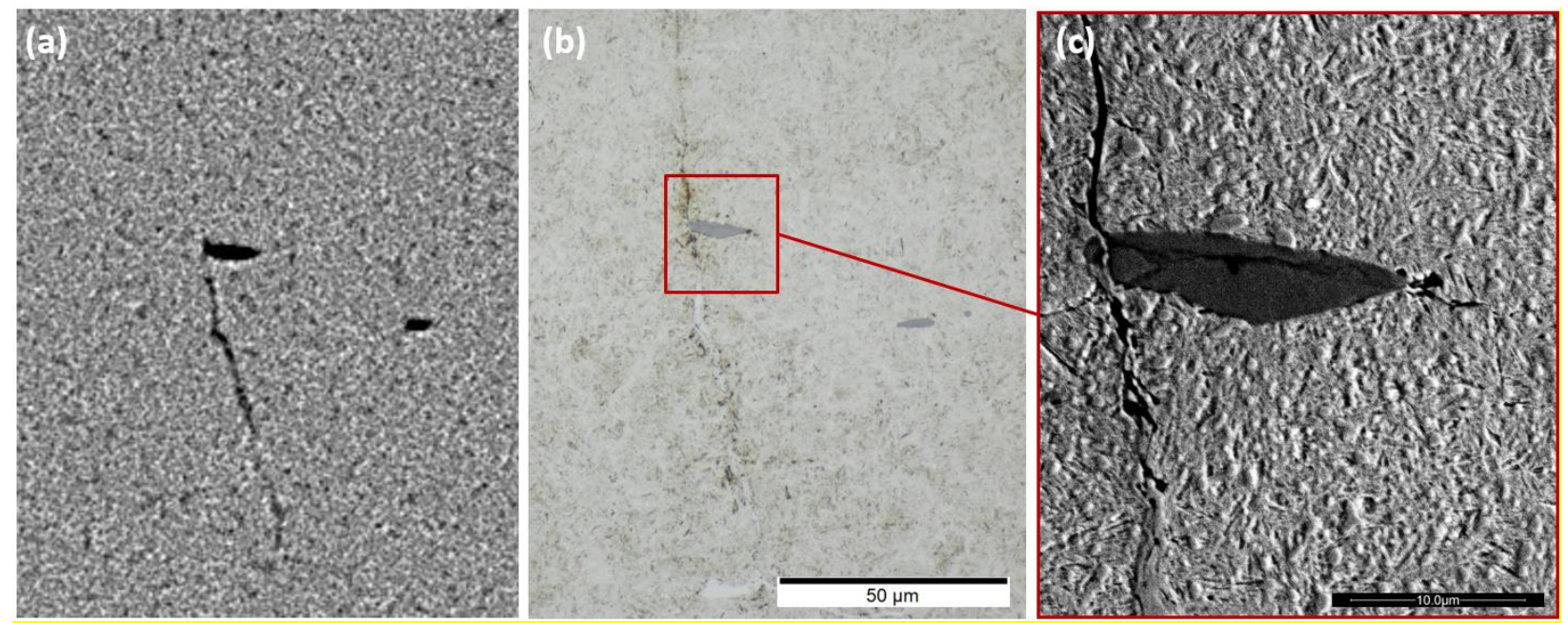

Fig. 13 (a) Tomography, (b) optical and (c) SEM images showing an inclusion interacting with a vertical segment of Crack 2

\subsection{Discussion}

The analysis of the wind turbine gearbox bearing presented in this study reveals some characteristics of WECs that can be used to help identify the role of different influencing factors that may contribute to the formation of this crack failure.

\subsection{Subsurface Cracking}

The fact that all of the observed cracks were contained within the sample edges and raceway obviously proves that these cracks initiated in the subsurface of the bearing. Furthermore, this shows that WEC formation in these bearings does not require a crack pathway from the bearing raceway, as was previously suggested [40, 43]. While this indicates that lubricant decomposition within crack face rubbing is likely not a driving mechanism for the WECs observed in this study, it does not preclude this driver for WECs in other applications or conditions. This result also does not eliminate lubricant composition or contamination as a cause of WECs, as it is still possible for lubricants to decompose within the contact to produce byproducts, such as hydrogen, that could diffuse into the steel causing embrittlement at some depth below the surface.

\subsection{Formation of WEA}

Beyond the location of the crack, additional information pertaining to the formation and propagation of WECs can be derived from this analysis. Of the four cracks identified in this sample Crack 4 was the smallest, spanning only $\sim 0.5 \mathrm{~mm}$ in the axial direction, consequently it can be assumed that this crack is in its earliest stage of formation when compared to the other three. Therefore, a detailed examination of Crack 4 could yield useful information as to the process of WEC formation. It was observed that there are multiple regions of DEA, as well as mixed regions of light and dark etching area alongside the WEA adjacent to this crack, micrographs of these regions are shown in Fig. 14. The authors have observed regions similar to these in [45,51], this further perpetuates the hypothesis that these local regions mixed and dark etching microstructure are precursors for the formation of nanograined WEA. If this is the case then the WECs studies here presumably would not have formed due to impact loads leading to the formation of adiabatic shear bands as discussed in [38-40]. This is because the high strain rate events which cause adiabatic shear bands would likely lead to an instantaneous change in the microstructure rather than a gradual transition from dark to white etching. 


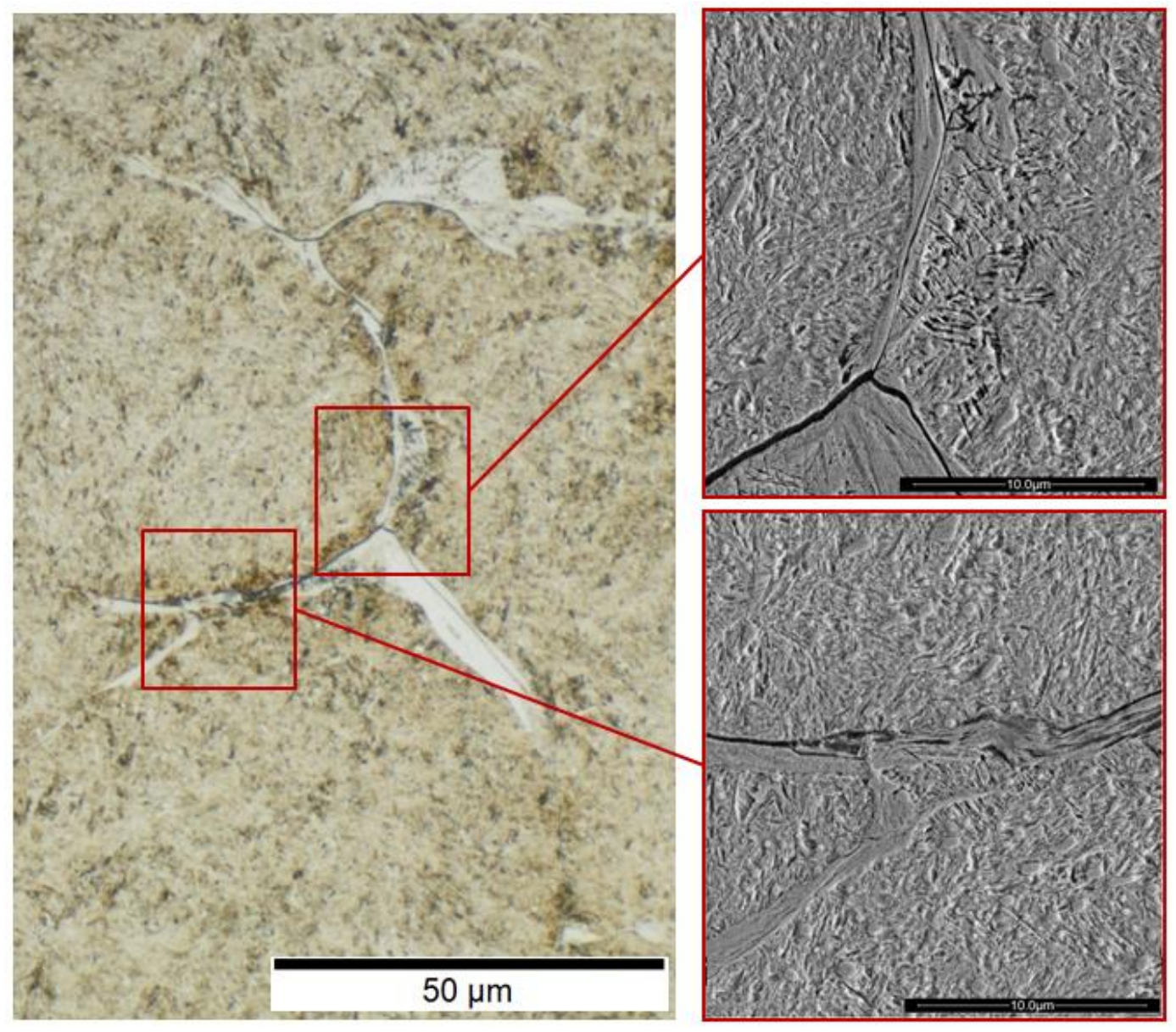

Fig. 14 An Etched optical image and two SEM micrographs showing the DEAs that accompanied the WEA surrounding Crack 4

\subsection{Crack Morphology}

It should also be noted that the morphology of the cracks observed in this sample have a jagged appearance with three-point branching, instances of this are shown in Fig. 9a, b, c, d, g, and h, Fig. 11, and Fig 13, as well as in Videos 1-8. This three point branching morphology is optically representative of cracks that are following preexisting austenitic grain boundaries. Cracking along grain boundaries is common in cases of embrittlement; however embrittlement is not necessary for this crack morphology to exist. The cracks also appear to be propagating vertically (perpendicular to the raceway) and along the axial plane of the bearing, this could explain why WECs appear as and described as 'axial cracks' once they reach the raceway surface. Additionally, the vertical nature of these cracks is not consistent with classical subsurface initiated rolling contact fatigue, where the crack trajectory there follows the angle of maximum subsurface stress caused by the contact. A vertical crack orientation would indicate that the stress state would be shifted so that there is a tensile stress in the circumferential direction.

\subsection{Inclusion Interaction}

Furthermore, X-ray tomography has been shown to be a useful tool in evaluating the interaction of the crack network with other inhomogeneities in the steel such as inclusions. Similar observations have been made in other studies mostly relying on physical serial cross sectioning [36]. In this previous work Evans et al, rigorously 
cataloged the inclusion/crack interaction and concluded that the WECs initiated at the inclusion and the branching of the crack network was the result of multiple butterfly cracks in close proximity linking together. Based on the observations of this current study it is unclear if the inclusions are initiation points for the WECs or if the WEC intersect the inclusion during propagation. The examples shown in Fig. 12 and Fig. 13 illustrate that both are plausible, however, further work would be needed to confirm the role that inclusions have in the initiation of WECs. Regardless of the mechanism for WEC formation, whether from mechanical conditions of operation or other externalities, inhomogeneities in the steel, such as inclusions, are likely to influence the formation of WEC failures.

\subsection{Conclusions}

1. High energy synchrotron X-ray tomography has been successfully used to non-destructively observe crack networks in samples extracted from field used AISI 52100 wind turbine bearings.

2. Four individual crack networks were observed remaining within the subsurface of the sample.

3. Selective cross sectioning of the sample was performed; optical and scanning electron microscopy of the WEC was used to confirm the presence of irregular microstructural alteration (WEA)

4. WECs in wind turbine bearings can be formed without connection to the bearing raceway surface; indicating that direct interaction of the crack face with the lubricant is not necessary to form WECs. However, this finding does not necessarily exclude surface initiated WECs as another possible formation mechanism.

5. The WECs observed in this study exhibited a characteristic morphology constituted by: vertical crack propagation, jagged three point branching, and multiple regions of mixed dark and light etching microstructure. Based on these observations it would seem unlikely that these cracks formed due impact loading leading to adiabatic shear band formation. Additionally, the short service life of this bearing, see [1], as well as the crack morphology, suggests running conditions that led to an accelerated fatigue that appears characteristically different from 'classical' rolling contact fatigue.

6. Multiple points of inclusions interaction were observed within the four branching WEC networks, some of these inclusions appeared to contribute to the direction of crack growth while some did not. Additionally inclusions surrounded by small amounts of cracking independent of the large branching WECs were observed, further investigation is needed to determine the role of inclusions in WEC formation.

Acknowledgments:

This work is supported by the U.S. Department of Energy Office of Energy Efficiency and Renewable Energy, Wind and Water Power Technology Office under Contract No. DE-AC02-06CH11357. The authors are grateful to DOE Project Managers Mr. Michael Derby and Mr. Nick Johnson for their support and encouragement. The authors would also like to acknowledge the assistance provided by our colleagues at Argonne National Laboratory's Tribology Section, especially Dr. Maria De La Cinta Lorenzo Martin for her assistance with electron microscopy and Dr. Oyelayo Ajayi for his helpful discussion on metallurgy. As well as Dr. David L. Burris of the University of Delaware's department of Mechanical Engineering for serving as an advisor over the course of this work. This research used resources of the Center for Nanoscale Materials and Advanced Photon Source, a U.S. Department of Energy (DOE) Office of Science User Facility operated for the DOE Office of Science by Argonne National Laboratory under Contract No. DE-AC02-06CH11357.

Compliance with Ethical Standards:

Funding: All presented analysis and results were funded by: Department of Energy Office of Energy Efficiency and Renewable Energy, Wind and Water Power Technology Office (Contract No. DE-AC02-06CH11357) 
References

[1] M.N. Kotzalas, G.L. Doll, Tribological advancements for reliable wind turbine performance, Philos. Trans. R. Soc. Lond. Math. Phys. Eng. Sci. 368 (2010) 4829-4850.

[2] J. Luyckx, W. Broeders, J. Geertsom, Method for increasing the fatigue strength of a predominantly steel mechanical part of a wind turbine and/or for reducing the tendency to form what are called "white etch cracks" or "brittle flakes" in such steel mechanical parts, US Pat. No US20090288742 A. 1 (2009).

[3] H. Uyama, H. Yamada, H. Hidaka, N. Mitamura, The effects of hydrogen on microstructural change and surface originated flaking in rolling contact fatigue, Tribol. Online. 6 (2011) 123-132.

[4] K. Iso, H. Miyajima, K. Denpou, Y. Toda, M. Yamazaki, M. Naka, Y. Fujita, Rolling bearing, rolling bearing for fuel cell, compressor for fuel cell system and fuel cell system, Google Patents, 2007.

[5] Y. Murakami, M. Naka, A. Iwamoto, G. Chatell, Long life bearings for automotive alternator applications, SAE Technical Paper, 1995.

[6] K. Tamada, H. Tanaka, Occurrence of brittle flaking on bearings used for automotive electrical instruments and auxiliary devices, Wear. 199 (1996) 245-252.

[7] H. Mikami, T. Kawamura, Influence of electrical current on bearing flaking life, SAE Technical Paper, 2007.

[8] S. Tanaka, Y. Murakami, Rolling bearing, US Pat. No US7435308 B2 (2008).

[9] A. Umeda, T. Shiga, K. Ihata, Rolling bearing incorporated in auxiliary device for internal combustion engine, US Pat. No US7618193 B2 (2009).

[10] W.J. Davies, K.L. Day, Surface fatigue in ball bearings, roller bearings, and gears in aircraft engines, in: Appl. Mech. Group Symp. Fatigue Roll. Contact Inst. Mech. Eng. Lond. Engl., 1963.

[11] A. Grabulov, R. Petrov, H.W. Zandbergen, EBSD investigation of the crack initiation and TEM/FIB analyses of the microstructural changes around the cracks formed under Rolling Contact Fatigue (RCF), Int. J. Fatigue. 32 (2010) 576-583.

[12] H. Harada, T. Mikami, M. Shibata, D. Sokai, A. Yamamoto, H. Tsubakino, Microstructural changes and crack initiation with white etching area formation under rolling/sliding contact in bearing steel, ISIJ Int. 45 (2005) 1897-1902.

[13] R. Osterlund, O. Vingsbo, L. Vincent, P. Guiraldenq, Butterflies in gatigued all bearings-formation mechanism and structure, Scand. J. Metall. 11 (1982) 23-32.

[14] P.C. Becker, Microstructural changes around non-metallic inclusions caused by rolling-contact fatigue of ball-bearing steels, Met. Technol. 8 (1981) 234-243.

[15] K. Hiraoka, M. Nagao, T. Isomoto, Study on flaking process in bearings by white etching area generation, J ASTM Int. 3 (2006) 1-7.

[16] A. Grabulov, U. Ziese, H.W. Zandbergen, TEM/SEM investigation of microstructural changes within the white etching area under rolling contact fatigue and 3-D crack reconstruction by focused ion beam, Scr. Mater. 57 (2007) 635-638.

[17] J.A. Martin, S.F. Borgese, A.D. Eberhardt, Microstructural alterations of rolling-bearing steel undergoing cyclic stressing, J. Fluids Eng. 88 (1966) 555-565.

[18] J.L. O'Brien, A.H. King, Electron microscopy of stress-induced structural alterations near inclusions in bearing steels, J. Fluids Eng. 88 (1966) 568-571.

[19] A. Greco, S. Sheng, J. Keller, A. Erdemir, Material wear and fatigue in wind turbine systems, Wear. 302 (2013) 1583-1591.

[20] T.B. Lund, J. Beswick, S.W. Dean, Sub-Surface Initiated Rolling Contact Fatigue-Influence of NonMetallic Inclusions, Processing History, and Operating Conditions, J. ASTM Int. 7 (2010) 102559. doi:10.1520/JAI102559. 
[21] K. Sugino, K. Miyamoto, M. Nagumo, K. Aoki, Structural alterations of bearing steels under rolling contact fatigue, Trans. Iron Steel Inst. Jpn. 10 (1970) 98.

[22] A. Grabulov, Fundamentals of rolling contact fatigue, TU Delft, Delft University of Technology, 2010.

[23] D. Scott, B. Loy, G.H. Mills, Paper 10: Metallurgical Aspects of Rolling Contact Fatigue, in: Proc. Inst. Mech. Eng. Conf. Proc., SAGE Publications, 1966: pp. 94-103.

[24] T. Endo, D. Dong, Y. Imai, Y. Yamamoto, Study on rolling contact fatigue in hydrogen atmosphereimprovement of rolling contact fatigue life by formation of surface film, Tribol. Interface Eng. Ser. 48 (2005) 343-350.

[25] R.H. Vegter, J.T. Slycke, The role of hydrogen on rolling contact fatigue response of rolling element bearings, J. ASTM Int. 7 (2009) 1-12.

[26] Y. Imai, T. Endo, D. Dong, Y. Yamamoto, Study on rolling contact fatigue in hydrogen environment at a contact pressure below basic static load capacity, Tribol. Trans. 53 (2010) 764-770.

[27] K. Hiraoka, T. Fujimatsu, N. Tsunekage, A. Yamamoto, Generation process observation of microstructural change in rolling contact fatigue by hydrogen-charged specimens, J. Jpn. Soc. Tribol. 52 (2007) 888-895.

[28] N. Kino, K. Otani, The influence of hydrogen on rolling contact fatigue life and its improvement, JSAE Rev. 24 (2003) 289-294.

[29] R. Errichello, R. Budny, R. Eckert, Investigations of bearing failures associated with white etching areas (WEAs) in wind turbine gearboxes, Tribol. Trans. 56 (2013) 1069-1076.

[30] K. Stadler, A. Stubenrauch, Premature bearing failures in industrial gearboxes, in: Antriebstechnisches Kolloqu. ATK, 2013: pp. 19-20.

[31] O.O. Ajayi, C. Lorenzo-Martin, R.A. Erck, G.R. Fenske, Scuffing mechanism of near-surface material during lubricated severe sliding contact, Wear. 271 (2011) 1750-1753. doi:10.1016/j.wear.2010.12.086.

[32] O.O. Ajayi, J.G. Hersberger, J. Zhang, H. Yoon, G.R. Fenske, Microstructural evolution during scuffing of hardened 4340 steel-implication for scuffing mechanism, Tribol. Int. 38 (2005) 277-282. doi:10.1016/j.triboint.2004.08.011.

[33] A. Oila, S.J. Bull, Phase transformations associated with micropitting in rolling/sliding contacts, J. Mater. Sci. 40 (2005) 4767-4774.

[34] J. Dobromirski, I.O. Smith, Metallographic aspects of surface damage, surface temperature and crack initiation in fretting fatigue, Wear. 117 (1987) 347-357. doi:10.1016/0043-1648(87)90154-2.

[35] J.J.C. Hoo, A.S. for T. and M.S.A. 28 on B. Steels, Bearing Steels: Into the 21st Century, ASTM International, 1998.

[36] M.-H. Evans, An updated review: white etching cracks (WECs) and axial cracks in wind turbine gearbox bearings, Mater. Sci. Technol. (2016) 1-37.

[37] K. Stadler, J. Lai, R. Vegter, A Review: The Dilemma With Premature White Etching Crack (WEC) Bearing Failures, in: Bear. Steel Technol. 10th Vol. Adv. Steel Technol. Roll. Bear., ASTM International, 2015.

[38] R. Errichello, S. Sheng, J. Keller, A. Greco, Wind Trubine Tribology: A Recap, U.S. Department of Energy, EERE Wind and Water Power Program, n.d. http://www.nrel.gov/docs/fy12osti/53754.pdf.

[39] J. Luyckx, Hammering Wear Impact Fatigue Hypothesis WEC/irWEA failure mode on roller bearings, (2011).

[40] S. Hyde, White Etch Areas: Metallurgical Characterization \& Atomistic Modeling, Wind Turbine Tribology Seminar, Argonne IL (2014).

[41] W. Solano-Alvarez, H. Bhadeshia, White-etching matter in bearing steel. Part II: distinguishing cause and effect in bearing steel failure, Metall. Mater. Trans. A. 45 (2014) 4916-4931.

[42] H. Bhadeshia, Steels for bearings, Prog. Mater. Sci. 57 (2012) 268-435. 
[43] M.-H. Evans, A.D. Richardson, L. Wang, R.J.K. Wood, Serial sectioning investigation of butterfly and white etching crack (WEC) formation in wind turbine gearbox bearings, Wear. 302 (2013) 15731582.

[44]T. Bruce, E. Rounding, H. Long, R.S. Dwyer-Joyce, Characterisation of white etching crack damage in wind turbine gearbox bearings, Wear. 338 (2015) 164-177.

[45] B. Gould, A. Greco, Investigating the Process of White Etching Crack Initiation in Bearing Steel, Tribol. Lett. 62 (2016) 1-14.

[46] A. Vincent, G. Lormand, P. Lamagnere, L. Gosset, D. Girodin, G. Dudragne, R. Fougeres, From white etching areas formed around inclusions to crack nucleation in bearing steels under rolling contact fatigue, in: Bear. Steels 21st Century, ASTM International, 1998.

[47] J. Gegner, Tribological aspects of rolling bearing failures, INTECH Open Access Publisher, 2011.

[48] J. Lai, E. loannides, J. Wang, Fluid-crack interaction in lubricated rolling-sliding contact, in: STLEASME 2008 Int. Jt. Tribol. Conf., American Society of Mechanical Engineers, 2008: pp. 437-439.

[49] B. Gould, A. Greco, Impact of Transient Slide-to-Roll Ratio Events in the Wind Turbine Application, (2014).

[50] A. Ruellan, F. Ville, X. Kleber, A. Arnaudon, D. Girodin, Understanding white etching cracks in rolling element bearings: The effect of hydrogen charging on the formation mechanisms, Proc. Inst. Mech. Eng. Part J J. Eng. Tribol. 228 (2014) 1252-1265.

[51] B. Gould, A. Greco, The Influence of Sliding and Contact Severity on the Generation of White Etching Cracks, Tribol. Lett. 60 (2015) 1-13.

[52] I. Strandell, C. Fajers, T. Lund, Corrosion-One Root Cause for Premature Failures, in: 37th LeedsLyon Symp. Tribol., 2010.

[53] J. Loos, I. Bergmann, M. Goss, Influence of currents from electrostatic charges on WEC formation in rolling bearings, Tribol. Trans. (2015).

[54] O. Bankestrom, Field Measurements for Wind Turbine Main Bearings, VDI Wissensforum COWEC. (2013) 18-19.

[55] W. Holweger, Progresses in solving White etching crack phenoma, NREL-Gearbox Reliab. Collab. Gold. Colo. (2014) 45.

[56] A.M. Diederichs, A. Schwedt, J. Mayer, T. Dreifert, Electron microscopy analysis of structural changes within white etching areas, Mater. Sci. Technol. (2016) 1-11.

[57] M. Ščepanskis, A. Jakovičs, I. Kaldre, W. Holweger, B. Nacke, A.M. Diederichs, The Numerical Model of Electrothermal Deformations of Carbides in Bearing Steel as the Possible Cause of White Etching Cracks Initiation, Tribol. Lett. 59 (2015) 1-10.

[58] M.-H. Evans, L. Wang, H. Jones, R.J.K. Wood, White etching crack (WEC) investigation by serial sectioning, focused ion beam and 3-D crack modelling, Tribol. Int. 65 (2013) 146-160.

[59] M.-H. Evans, A.D. Richardson, L. Wang, R.J.K. Wood, W.B. Anderson, Confirming subsurface initiation at non-metallic inclusions as one mechanism for white etching crack (WEC) formation, Tribol. Int. 75 (2014) 87-97.

[60] L. Babout, W. Ludwig, E. Maire, J.Y. Buffière, Damage assessment in metallic structural materials using high resolution synchrotron X-ray tomography, Nucl. Instrum. Methods Phys. Res. Sect. B Beam Interact. Mater. At. 200 (2003) 303-307. doi:10.1016/S0168-583X(02)01692-0.

[61] T.J. Marrow, L. Babout, A.P. Jivkov, P. Wood, D. Engelberg, N. Stevens, P.J. Withers, R.C. Newman, Three dimensional observations and modelling of intergranular stress corrosion cracking in austenitic stainless steel, J. Nucl. Mater. 352 (2006) 62-74. doi:10.1016/j.jnucmat.2006.02.042.

[62] R.K. Everett, K.E. Simmonds, A.B. Geltmacher, Spatial distribution of voids in HY-100 steel by X-ray tomography, Scr. Mater. 44 (2001) 165-169. doi:10.1016/S1359-6462(00)00561-3. 
[63] E. Maire, O. Bouaziz, M. Di Michiel, C. Verdu, Initiation and growth of damage in a dual-phase steel observed by X-ray microtomography, Acta Mater. 56 (2008) 4954-4964. doi:10.1016/j.actamat.2008.06.015.

[64] S.M. Ghahari, A.J. Davenport, T. Rayment, T. Suter, J.-P. Tinnes, C. Padovani, J.A. Hammons, M. Stampanoni, F. Marone, R. Mokso, In situ synchrotron X-ray micro-tomography study of pitting corrosion in stainless steel, Corros. Sci. 53 (2011) 2684-2687. doi:10.1016/j.corsci.2011.05.040.

[65] P.J. Schilling, B.R. Karedla, A.K. Tatiparthi, M.A. Verges, P.D. Herrington, X-ray computed microtomography of internal damage in fiber reinforced polymer matrix composites, Compos. Sci. Technol. 65 (2005) 2071-2078. doi:10.1016/j.compscitech.2005.05.014.

[66] J.-Y. Buffière, E. Maire, P. Cloetens, G. Lormand, R. Fougères, Characterization of internal damage in a MMCp using X-ray synchrotron phase contrast microtomography, Acta Mater. 47 (1999) 16131625. doi:10.1016/S1359-6454(99)00024-5.

[67] C.F. Martin, C. Josserond, L. Salvo, J.J. Blandin, P. Cloetens, E. Boller, Characterisation by X-ray micro-tomography of cavity coalescence during superplastic deformation, Scr. Mater. 42 (2000) 375-381. doi:10.1016/S1359-6462(99)00355-3.

[68] A. Greco, B. Gould, R. Preisler, White-Etching Crack Failure Overview, Tomography Analysis, and Test Development, Wind Turbine Tribology Seminar Argonne IL (2014).

[69] X. Xiao, F. Fusseis, F. De Carlo, X-ray fast tomography and its applications in dynamical phenomena studies in geosciences at Advanced Photon Source, in: SPIE Opt. Eng. Appl., International Society for Optics and Photonics, 2012: p. 85060K-85060K.

[70] B.A. Dowd, G.H. Campbell, R.B. Marr, V.V. Nagarkar, S.V. Tipnis, L. Axe, D.P. Siddons, Developments in synchrotron $x$-ray computed microtomography at the National Synchrotron Light Source, in: SPIEs Int. Symp. Opt. Sci. Eng. Instrum., International Society for Optics and Photonics, 1999: pp. 224-236..

[71] D. Gürsoy, F. De Carlo, X. Xiao, C. Jacobsen, TomoPy: a framework for the analysis of synchrotron tomographic data, J. Synchrotron Radiat. 21 (2014) 1188-1193.

[72] B. Münch, P. Trtik, F. Marone, M. Stampanoni, Stripe and ring artifact removal with combined wavelet - Fourier filtering, Opt. Express. 17 (2009) 8567-8591. doi:10.1364/OE.17.008567.

[73] D. Paganin, S.C. Mayo, T.E. Gureyev, P.R. Miller, S.W. Wilkins, Simultaneous phase and amplitude extraction from a single defocused image of a homogeneous object, J. Microsc. 206 (2002) 33-40. 


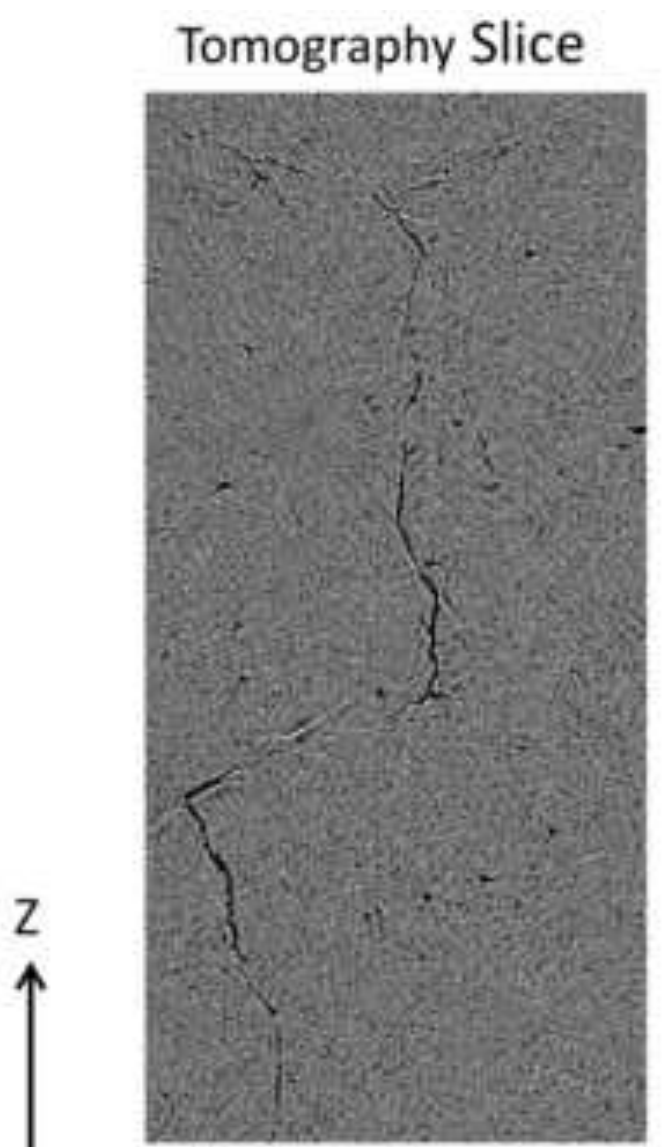

\section{Etched Cross-Section}
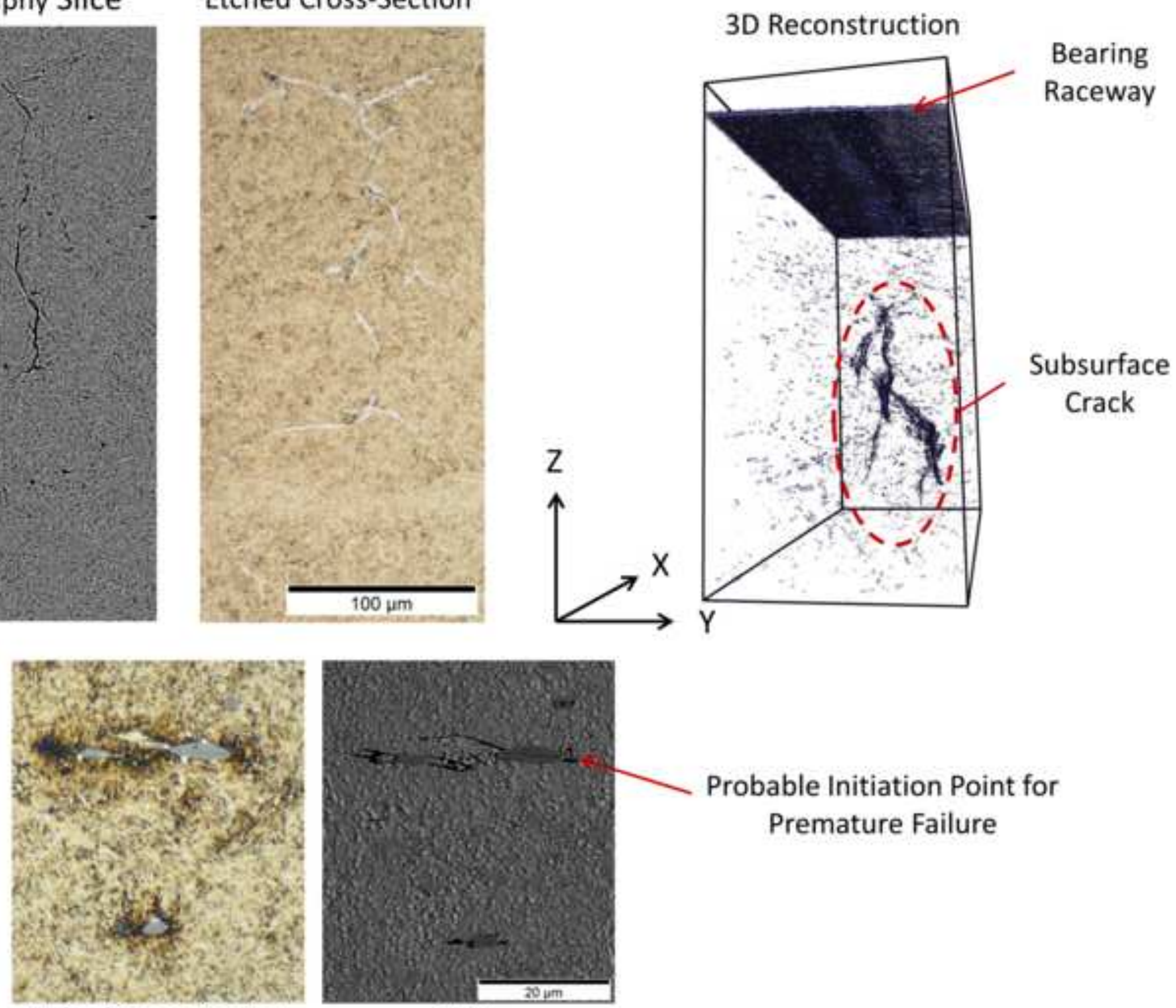

Etched Cross-Section

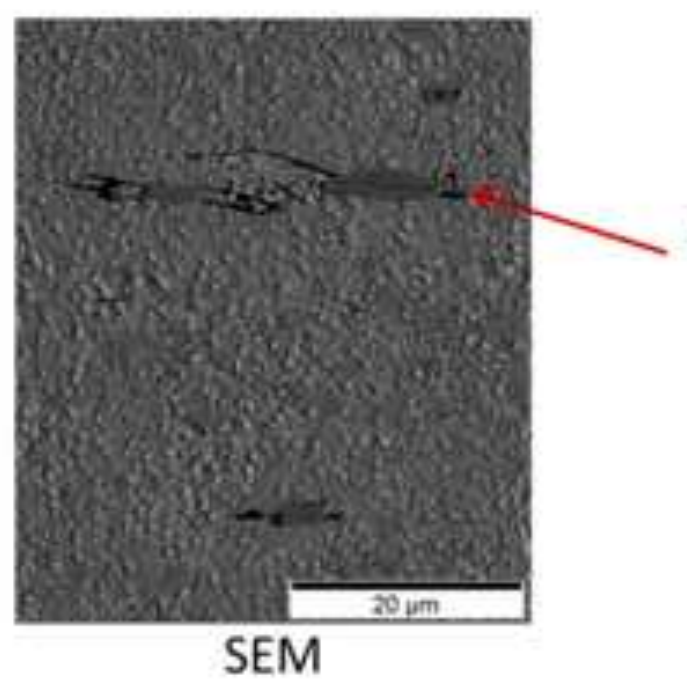

Probable Initiation Point for Premature Failure 